\title{
Assisted Reproduction and the Legal Recognition of Multiple Parents: A Comparative Analysis
}

by

Philip D Bremner LLB (Hons), LLM (by research) (Aberdeen)

Submitted to the School of Law, University of Exeter as a Dissertation towards the degree of Master of Research by advanced study in Socio Legal Research, September 2011.

I certify that all material in this dissertation which is not my own work has been identified with appropriate acknowledgement and referencing and I also certify that no material is included for which a degree has previously been conferred upon me. 


\begin{abstract}
Assisted reproduction technology (ART) creates an opportunity for the creation of co-parenting arrangements involving donors and surrogates. Donor and surrogate involvement in the lives of children born using ART has received increased media attention recently and is a matter of considerable social significance. This dissertation attempts to test the law's restriction to two parents in light of the potential for co-parenting arrangements. In order to do this, it adopts a socio-legal approach by considering the law within its social context and using empirical research methods to canvass opinion in relation to this from appropriate purposively selected research participants.
\end{abstract}

The study employed a mixed methods approach, using an online questionnaire and telephone interviews, to collect empirical data on the views of people who have become (or intend to become) parents using ART, in relation to donor/surrogate involvement and legal recognition. These data were analysed using a constructivist grounded theory approach in order to generate theory from data and explore how participants construct and interpret their own social reality.

This was necessarily a small-scale project that nevertheless successfully captured a range of views in relation to donor/surrogate involvement and legal recognition. The overall impression from the data was that co-parenting may not be a particularly attractive concept for heterosexual couples but it might be something that same-sex couples would seek. The study also highlighted the need for further research in this area, particularly in relation to same-sex couples.

Word Count: 17930 


\section{Table of Contents}

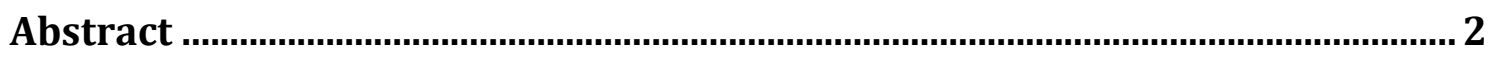

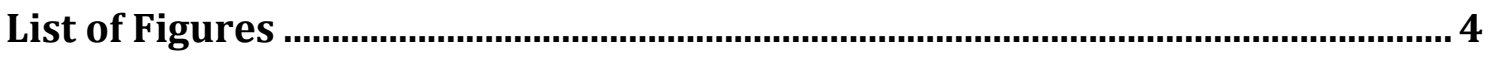

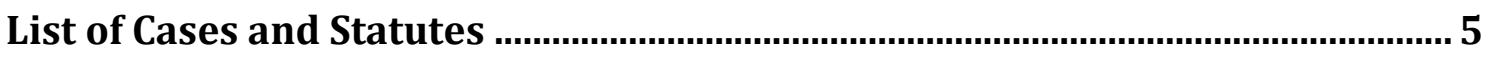

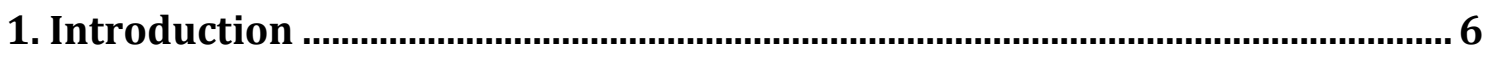

2. Literature Review ..............................................................................12

2.1 Introduction .................................................................................................. 12

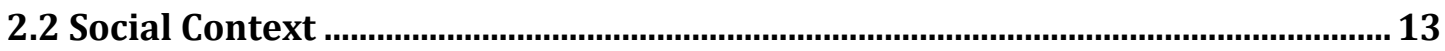

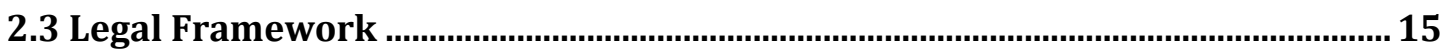

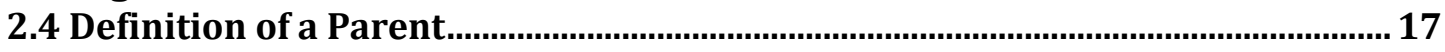

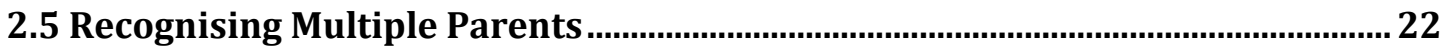

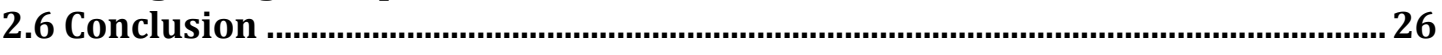

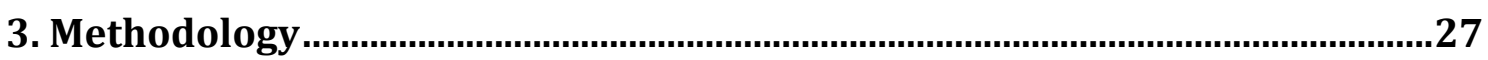

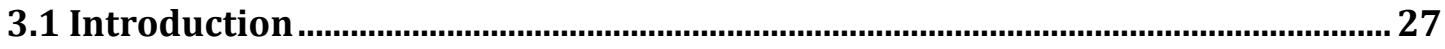

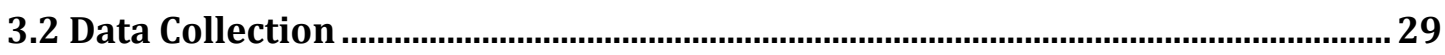

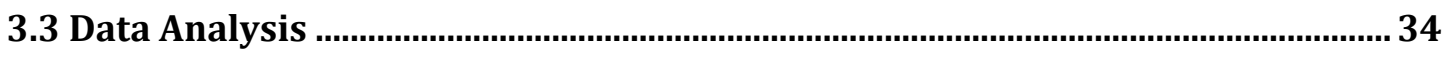

3.4 Ethical Considerations ............................................................................................. 36

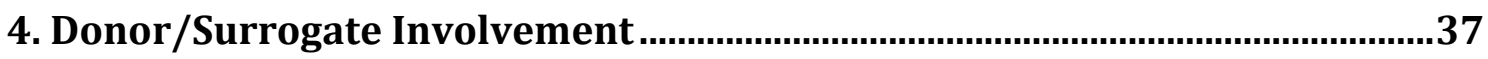

4.1 Introduction ........................................................................................................... 37

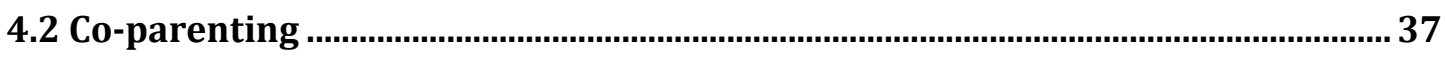

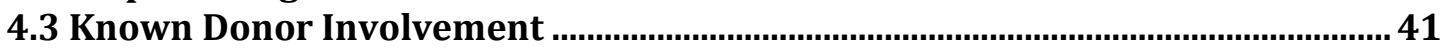

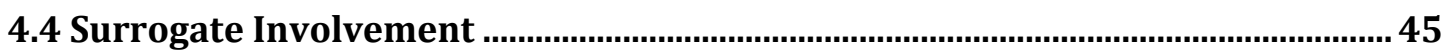

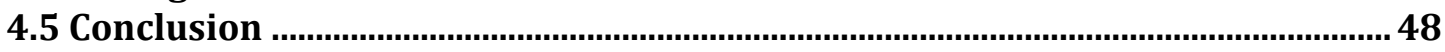

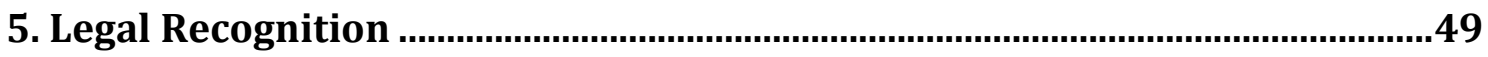

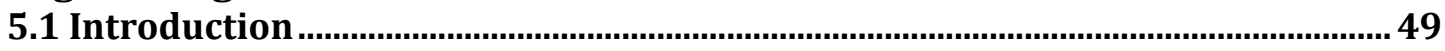

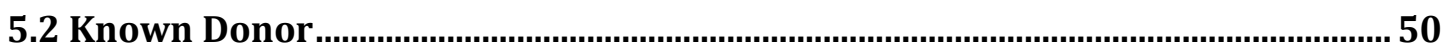

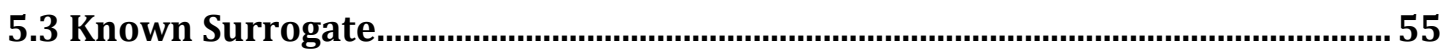

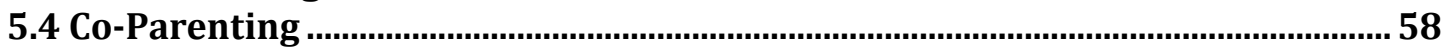

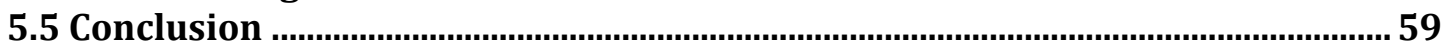

6. Conclusion .........................................................................................................61

Appendix 1: Information Sheet, Consent Form and Questionnaire ..................63

Appendix 2: Example Interview Guide ..................................................................75

Appendix 3: Table of Participants' Jurisdiction ...................................................78

Appendix 4: Chi Square Contingency Tables - Friends as Donors and

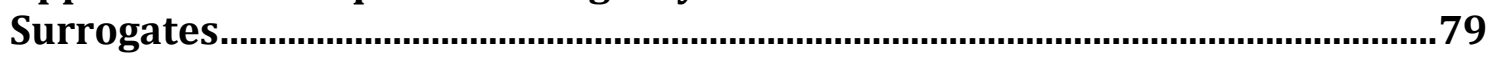

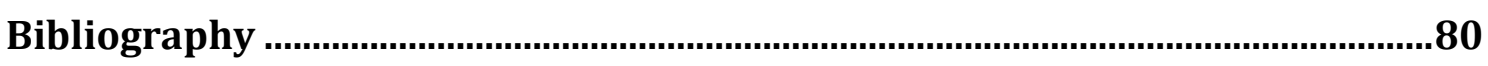




\section{List of Figures}

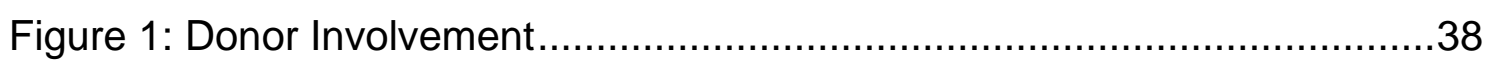

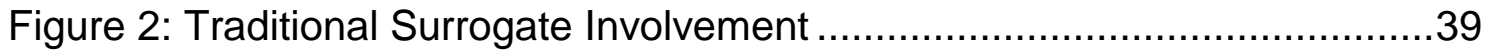

Figure 3: Gestational Surrogate Involvement....................................39

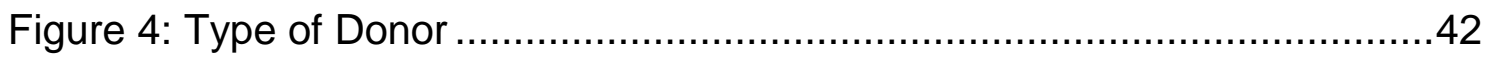

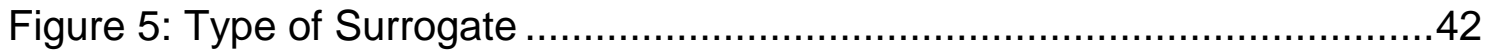

Figure 6: Legal Recognition of Known Donor ......................................49

Figure 7: Legal Recognition of Traditional Surrogate ..............................49

Figure 8: Legal Recognition of Gestational Surrogate ...............................50 


\section{List of Cases and Statutes}

\section{Statutes and Conventions}

Californian Family Code (UPA), Part 3, Division 12

Children's Act 1989

European Convention on Human Rights 1950

European Convention on the Legal Status of Children Born Out of Wedlock 1975

Family Law Reform Act 1969

Human Fertilisation and Embryology Act 2008

Human Fertilisation and Embryology Authority (Disclosure of Donor Information)

Regulations 2004

United Nations Convention on the Rights of the Child 1989

Surrogacy Arrangements Act 1985

\section{Cases}

Ampthill Peerage Case [1977] AC 547

$A A v B B 2007$ ONCA 2

Elisa $B 37$ Cal 4th 108

Huang $v$ Secretary of State for the Home Department [2007] UKHL 11

In re Marriage of Buzzanca (1998) 72 Cal Rptr 2d, 282

Jacob vs Schultz-Jacob 2007 PA Super 118

Johnson v Calvert (1993) 5 Cal 4th 84

Re $D$ [2006] EWHC 2 (Fam)

Re G [2006] UKHL 43 


\section{Introduction}

Families are important within society. ${ }^{1}$ It is within the family that 'we negotiate an urgent need for belonging with an equally urgent need for autonomy'. ${ }^{2}$ There is considerable debate, however, about what constitutes a family. ${ }^{3}$ Some seek to define a family based on the traditional hetero-normative nuclear family. Such a definition relies heavily on formal structures such as marriage. ${ }^{4}$ This might suggest a model of family law that privileges and supports formalised unions within families over mere cohabitation. This definition, however, can lead to the disenfranchisement of people who consider themselves to be families but do not fall within this definition. As Douglas highlights, "non-recognition is equally important to the discussion... what is left out may be as important as what is included, in understanding the content of family law and the messages it may send.' 5

One of the central features of the family, and thus one of the main areas of concern for family law, is the parent-child relationship. ${ }^{6}$ Children are seen as an intrinsic part of what constitutes a family. ${ }^{7}$ There is, however, considerable controversy as to who qualifies as a parent. ${ }^{8}$ This is an important issue in family law because legal parenthood is considered as being that which 'makes the

\footnotetext{
${ }^{1}$ This statement has received Government recognition from both the current Coalition and previous Labour Government (see Daily Telegraph, 'David Cameron: family matters to children more than income' 11 January 2010; and Cabinet Office, Families in Britain (The Stationary Office, London 2008)). It has also been recognised by the House of Lords (see Huang $v$ Secretary of State for the Home Department [2007] UKHL 11 [18]). See also Jonathan Herring, Family law (Longman law series, 5th edn Longman, Harlow 2011) 1.

2 Alison Diduck, Law's Families (Butterworths law in context series, Butterworths, London 2003) 1.

${ }^{3}$ See Jonathan Herring, Family law (Longman law series, 5th edn Longman, Harlow 2011) 1 for a more detailed discussion.

${ }^{4}$ See Lisa Glennon. "Obligations between adult partners: Moving from form to function?' (2008) 22(1) International Journal of Law, Policy and the Family 22 for a discussion of the relevance of this view to modern families.

5 Gillian Douglas, An introduction to family law (Clarendon law series, 2nd edn Oxford University Press, Oxford 2004) 228.

${ }^{6}$ For discussions on how parenthood has replaced marriage as the central organizing concept of family law see Lisa Glennon. "Obligations between adult partners: Moving from form to function?' (2008) 22(1) International Journal of Law, Policy and the Family 22, 24 and John Eekelaar and Mavis Maclean (eds), Family law (Oxford readings in socio-legal studies, Oxford University Press, Oxford 1994) 18.

${ }^{7}$ See Andrew Bainham. 'Family Law in a Pluralistic Society' (1995) 22 Journal of Law and Society 234, 244 and Sue Dyson, The option of parenthood (Sheldon, London 1993) 13. ${ }^{8}$ See for example Emily Jackson, 'What is a Parent?' in Alison Diduck and Katherine O'Donovan (eds), Feminist Perspectives on Family Law (Routledge-Cavendish, London 2006) 59 and Andrew Bainham and others, What is a parent? : a socio-legal analysis (Hart Pub., Oxford 1999) 297.
} 
child a member of a family, generating for that child a legal relationship with wider kin going well beyond the parental relationship'. ${ }^{9}$ Therefore, the way in which the law confers legal parenthood is significant because this determines whether children and potential parents are considered as part of a family unit.

The importance of the parent-child relationship has been highlighted in the context of post-separation families. ${ }^{10}$ In addition, problems can arise in stepfamilies as a result of the lack of automatic legal recognition of the relationship between step-parent and child. ${ }^{11}$ The issue of who is considered to be a child's parent is especially significant, however, in the context of families created through artificial reproduction. There are different forms of artificial reproduction used by different types of families, each with different consequences for the legal recognition of the parent-child relationship. In a sense any type of artificial reproduction raises potential complications for the question of who is to be considered the parent because artificial reproduction separates biological/genetic relatedness from the intention to care for a child. ${ }^{12}$ However, the complications associated with legal parenthood affect alternative families ${ }^{13}$ particularly strongly because for them it is a matter of being recognised as a valid family. ${ }^{14}$

Heterosexual couples who make use of artificial reproductive technology of whatever sort face difficulties in relation to the child's right to know about his or her genetic origin. ${ }^{15}$ However, they may choose to conceal the child's means of conception and thereby appear to conform to the traditional hetero-normative image of the family. By contrast, same-sex couples must face up to the reality of

\footnotetext{
9 Andrew Bainham, 'Parentage, Parenthood and Parental Responsibility: Subtle, Elusive Yet Important Distinctions' in Andrew Bainham, Shelley Day Sclater and Martin Richards (eds), What is a parent? : a socio-legal analysis (Hart Pub., Oxford 1999) 33.

${ }^{10}$ For a discussion of the importance for the welfare of the child of maintaining a relationship with each parent following divorce see Martin Richards, 'Divorcing Children: Roles for Parents and the State' in Mavis Maclean and Jacek Kurczewski (eds), Families, politics and the law : perspectives for East and West Europe (Clarendon, Oxford 1993) 308.

11 Marjorie Smith. 'New Stepfamilies - a descriptive study of a largely unseen group' (2003) 15(2) Child and Family Law Quarterly 185, 196.

12 Jonathan Herring, Family law (Longman law series, 5th edn Longman, Harlow 2011) 322.

${ }^{13}$ Alternative families (or non-traditional families) here is contrasted with traditional nuclear families and especially refers to same-sex couples. See Barbara Cox, 'Alternative Families' (2000) Wisconsin Women's Law Review 93, 95

${ }_{14}$ Aleardo Zanghellini. 'Lesbian and Gay Parents and Reproductive Technologies: The 2008 Australian and UK Reforms' (2010) 18(3) Feminist Legal Studies 227, 229.

15 Caroline Jones, 'The identification of "parents" and "siblings": new possibilities under the reformed Human Fertilisation and Embryology Act ' in Julie A. Wallbank, Shazia Choudhry and Jonathan Herring (eds), Rights, gender, and family law (Routledge, Abingdon 2010) 292.
} 
their child's means of conception. This does not necessitate that other participants in the artificial reproduction process (such as sperm/egg donor or surrogate) need to be involved in the child's life, just as the position that opposite-sex couple are in, does not necessitate that such people should be excluded. However, a number of same-sex couples, perhaps because of the undeniable reality of how the child was conceived, are choosing to engage in co-parenting projects with the other participant(s) in the artificial reproduction process. ${ }^{16}$

This study is situated within the now well-established tradition of socio-legal research in family law. ${ }^{17}$ As such, it goes beyond the mere analysis of legal doctrine and considers the social context in which the law operates. In order to achieve this, empirical data will be collected. However, as Eekelaar and Maclean highlight, the collection of empirical data would be insufficient in itself to make this a rigorous socio-legal study:

socio-legal studies implies much more than assembling empirical information about how legal institutions work or describing what lawyers or other actors say that they do. The way in which such knowledge is sought, how it is interpreted, and the use to which it is put occur within a wider set of values and objectives. ${ }^{18}$

In light of this, the empirical data that are gathered will be discussed within an interpretive theoretical framework drawing on socio-legal theory. ${ }^{19}$ In this way the study will consider aspects of the law surrounding parenthood as a 'study of a field of social experience' 20 rather than as a purely regulatory framework. As such, the study will explore not only whether parenthood following ART is regulated in an appropriate way but also the ways in which the law impacts on our understanding of parenthood. This accords with Cotterrell's view of sociolegal studies which is designed to "contribute to theoretical analysis of the

\footnotetext{
16 See $A A$ v BB (2007) ONCA 2 and Deborah Dempsey, 'Conceiving and Negotiating Reproductive Relationships: Lesbians and Gay Men Forming Families with Children' (2010) 44 Sociology 1145.

17 For a discussion of the various socio-legal studies in family law see Alison Diduck, Law's Families (Butterworths law in context series, Butterworths, London 2003) vi.

18 John Eekelaar and Mavis Maclean (eds), Family law (Oxford readings in socio-legal studies, Oxford University Press, Oxford 1994) 1.

19 See Chapter 5: Legal Recognition p $58-59$.

20 Roger Cotterrell. 'Subverting Orthodoxy, Making Law Central: A View of Sociolegal Studies' (2002) 29 Journal of Law and Society 632, 633.
} 
nature of law in society, to a deeper understanding of legal doctrines and institutions in general...21

Methodologically speaking, this study is influenced by the feminist social constructionist research culture. This highlights the way in which social practices are a product of culture rather than nature and can be created and influenced by the law. As Lacey highlights, '[f]eminist legal theorists are hence of the view that gender relations are open to revision through the modification of powerful social institutions such as law'. ${ }^{22}$ On this basis, the study will consider individual family practices ${ }^{23}$ and the effect that law has in constituting these practices. The study will demonstrate that the law of parenthood is attempting to impose a model of the family that privileges the homo-nuclear sexual family model, ${ }^{24}$ which may have the effect of excluding certain family forms within society.

The recognition of multiple parents relates to the definition of the family that the law should adopt. By granting formal recognition to each of the adults who intended to care for the child from the start the law would be adopting a more functional approach to the family. This approach is advocated as an alternative to the formalist approach mentioned earlier. ${ }^{25}$ The legal definition of the family, and of parenthood, should not necessarily depend on our everyday understanding of these terms, firstly because how these terms are interpreted may differ and reflect differing values and beliefs ${ }^{26}$ and secondly because this fails to appreciate the characteristic role these terms play within family law. In this regard, Hart's admonition that legal theory should not be built on the definition of legal terms abstracted from their function within the legal system seems apposite. ${ }^{27}$ By allowing for the possibility of more than two parents in the context of assisted reproduction the law would be dealing with 'the

21 Roger Cotterrell, Law's community : legal theory in sociological perspective (Oxford sociolegal studies, Clarendon, Oxford 1995) 77.

22 Nicola Lacey, Unspeakable subjects : feminist essays in legal and social theory (Hart, Oxford 1998) 3.

${ }^{23}$ For the importance of this see D. H. J. Morgan, Family connections : an introduction to family studies (Polity, Cambridge 1996).

24 Martha Albertson Fineman, The neutered mother, the sexual family, and other twentieth century tragedies (Routledge, New York ; London 1995) 143.

${ }^{25}$ Lisa Glennon. 'Fitzpatrick v. Sterling Housing Association LTD - An Endorsement of the Functional Family' (2000) 14 International Journal of Law, Policy and the Family 226.

26 Jonathan Herring, Family law (Longman law series, 5th edn Longman, Harlow 2011) 2.

27 H. L. A. Hart, 'Definition and Theory in Jurisprudence' in Essays in jurisprudence and philosophy (Clarendon, Oxford 1983). 
consequences of "caring and sharing"' 28 that are created in such co-parenting arrangements by legally recognising the role that these adults are already playing in the child's life as social parents.

This dissertation aims to examine the law's approach to parentage following ART in these two jurisdictions and to explore the views of people who have made use of such technology in relation to donor/surrogate involvement in their children's lives. Through the use and analysis of self-completion questionnaires, the study attempts to gauge how desirable donor/surrogate involvement is as well as the level of legal recognition this deserves. Follow-up semi-structured interviews are used to explore in more depth participant's reasons and motivations for these views. Finally participant's responses to the current level of legal recognition in each jurisdiction will be examined through the use of vignettes in both the questionnaires and interviews.

This situation, where three (or potentially more) adults seek recognition as the child's parents has not been adequately addressed in the law of England and Wales, which limits the number of parents a child has to two. ${ }^{29}$ This dissertation will critically evaluate the rationale for limiting the number of parents in this way and assess whether there is sufficient justification for preventing additional parents to be recognised in law. The following chapter will consider the basis on which parenthood should be conferred. It will do this by discussing previous empirical research and academic articles on parenthood and assisted reproduction as well as the judicial framework that currently operates in England and Wales ${ }^{30}$ and California. ${ }^{31}$ After outlining this studies methodological approach in chapter three, the study will go on to discuss the results of the empirical study in relation to views on donor/surrogate involvement and legal recognition in chapters four and five respectively.

\footnotetext{
28 Anne Bottomley and Simone Wong (eds), Changing contours of domestic life, family and law : Caring and sharing (Oñati international series in law and society, Hart Publishing, Oxford 2009) 4.

29 See Julie McCandless and Sally Sheldon. 'The Human Fertilisation and Embryology Act (2008) and the Tenacity of the Sexual Family' (2010) 73(2) MLR 175, 193.

${ }^{30}$ Referred to as E\&W throughout the paper.

31 This will allow for comparison of two systems that limit the number of parents to two but allocate legal parenthood in different ways in order to reflect on how the law in England and Wales might be reformed. For more details on the selection of these jurisdictions and the legal framework see Chapter 2: Literature Review pp $16-17$.
} 
The reform of legal parentage resulting from assisted reproduction is currently a highly topical and controversial issue. ${ }^{32}$ There is a growing realisation that increasingly out-dated legal rules are no longer instep with social reality. ${ }^{33}$ This issue is of considerable significance to society because it extends beyond the rights of parents and impacts on the rights of children, which there is a clear political mandate to protect. ${ }^{34}$ As Professor Lowe highlights, 'children do not live in a vacuum, but within a family and an important part of their protection is that the family unit, no matter what form it takes, enjoys adequate and equal legal recognition and protection. In other words, it is as discriminating to the child to limit legal parenthood or to deny significant carers legal right and responsibilities as to accord the child a different status and legal rights according to the circumstance of their birth or upbringing'. ${ }^{35}$ This goes to the very heart of family law and engages tensions within the European Convention on Human Rights, which guarantees the right to marry and found a family ${ }^{36}$ as well as a right to private and family life. ${ }^{37}$ This study aims to investigate the possibility of recognising more than two parents so that alternative families who wish to engage in co-parenting arrangements with the donor/surrogate are not marginalised and forced to do so without any legal protection. ${ }^{38}$

32 Craig Lind and Tom Hewitt. 'Law and the complexities of parenting: parental status and parental function' (2009) 31(4) Journal of Social Welfare and Family Law 391.

33 Jenni Millbank. 'The Limits of Functional Family: Lesbian Mother Litigation in the Era of the Eternal Biological Family' (2008) 22 International Journal of Law, Policy and the Family 149; Loveday Hodson and ILGA Europe. 'The Rights of Children Raised in Lesbian, Gay, Bi-sexual or Transgender Families: A European Perspective' (2008)

$<$ www.llgaeurope.org/content/download/.../2/.../Children's+Report 03.pdf> accessed 2

September 2011.

34 European Convention on the Legal Status of Children Born Out of Wedlock 1975 ; United Nations Convention on the Rights of the Child 1989 ; Geraldine Van Beuren. 'Child Rights in Europe, Convergence and Divergence in Judicial Protection' (Strasbourg 2008) .

35 Nigel Lowe. 'A study into the rights and legal status of children being brought up in various forms of marital or non-marital partnerships and cohabitation: A Report for the attention of the Committee of Experts on Family Law of the Council of Europe ' (Strasbourg 2009)

$<$ http://www.coe.int/t/DGHL/STANDARDSETTING/FAMILY/CJ-

FA\%20 $2008 \% 205 \% 20$ E\%2025\%2009\%2009.pdf> accessed 2 September 2011 accessed 2 September 2011.

36 European Convention on Human Rights art 12.

37 lbid art 8.

${ }^{38}$ Although this is not a central issue in the present study, the issue of co-parenting may be of some relevance to single parents who wish to involve the donor/surrogate in their children's lives. 


\section{Literature Review}

\subsection{Introduction}

The question of what a parent is has been the subject of much academic discussion both in general family law and in the assisted reproduction context. Who is legally considered a child's parent is determined by legislation and case law. Although this has an impact on who society and individual families consider to be a parent, legal and social recognition do not necessarily entirely correspond to one another. The concept of a parent is socially constructed and one of the factors that influences this is legal recognition. ${ }^{39}$ However, individual family practices also play a part in who constitutes a parent in the eyes of a given family. Both individual family practices and the legal framework that regulates them exist within a given social context, which varies depending on the jurisdiction. Different jurisdictions have adopted different approaches to the issue of parentage following assisted reproduction. California, for example, seems to adopt a more intent-based approach to surrogacy than E\&W, which may be partly attributable to the different social context surrounding surrogacy in these two jurisdictions. This point will be explored in more detail in the following section. ${ }^{40}$

This section will begin by outlining the legal framework that determines legal parenthood in E\&W and California and the social context in which the law operates. In each jurisdiction the primary legislation has been interpreted to a greater or lesser extent by the courts resulting in divergent approaches. It is important to appreciate the legal context in which families within these jurisdictions exist because this will provide the background for interpreting the empirical data gathered in each of the jurisdictions. However, it is also important to consider the social context within which the law operates, which will also be explored in this chapter. This can be useful when attempting to explain differences in approach between the two jurisdictions. For this reason a sociolegal approach to the research is appropriate in order to be able to consider how

${ }^{39}$ Katharine Baker, 'Bionormativity and the Construction of Parenthood' (2008) 42 Georgia Law Review 649.

40 See pp $15-17$. 
the law actually operates within these different jurisdictions and also what values underpin the varying legal approaches. ${ }^{41}$

Following on from this, the section will consider the academic literature on the definition of a parent. Much of the discussion around parenthood considers post-separation families, step-families and adoption. These discussions highlight many of the same issues that are raised in the assisted reproduction context and are, therefore, highly relevant in the present context. This will feed into a discussion of the correct basis for identifying who should be considered a parent. This is no simple matter and involves deciding between competing claims such as a biological connection, the intention to procreate and the psychological/caring relationship that exists with the child. Having discussed who should be recognised as a parent, the section will go on to consider the possibility of recognising more than two parents. This will involve analysing the academic commentary on the subject as well as empirical studies particularly in the assisted reproduction context, using an interdisciplinary approach. This section, as with the whole dissertation, adopts a comparative approach in that it will consider academic literature and studies from California, as well as E\&W, drawing on other jurisdictions to supplement the analysis where appropriate.

\subsection{Social Context}

Estimates by the HFEA suggest that infertility affects between 1 in 6 and 1 in 7 couples in the United Kingdom, ${ }^{42}$ which is similar to the number affected in the United States. ${ }^{43}$ This has resulted in approximately 2,000 children per year being born in the UK as a result of gamete donation. ${ }^{44}$ In the United States, over 7,000 children were born in 2008 using egg donation alone. ${ }^{45}$ The number of children born through surrogacy is lower but remains significant. In the United

\footnotetext{
41 Reza Banakar and Max Travers, Theory and method in socio-legal research (Oñati international series in law and society, Hart Publishing, Oxford 2005) xi. See also CM Campbell and Paul Wiles. 'The Study of Law in Society in Britain' (1976) 10 Law and Society Review 553. ${ }^{42}<$ http://www.hfea.gov.uk/infertility-facts.htm|\#1248> accessed 1 September 2011.

${ }^{43}<$ http://www.uptodate.com/contents/patient-information-evaluation-of-the-infertile-couple> accessed 1 September 2011.

${ }^{44}<$ http://www.hfea.gov.uk/donor-conception-births.html> accessed 1 September 2011. This includes both sperm and egg donation.

${ }^{45}<$ http://www.cdc.gov/art/ART2008/PDF/ART 2008 Full.pdf> p 91 accessed 1 September 2011. Only the statistics for egg donation were readily available in the United States because the Centers for Disease Control and Prevention do no include artificial insemination in their definition of ART.
} 
Kingdom estimates vary between 700 and 1000 surrogacy births since $1985 .{ }^{46}$ In the United States the number is significantly higher with over 5,000 births from gestational surrogacy between 2004 and $2008 .{ }^{47}$ The highest proportion of these births, $23 \%$, were in California. ${ }^{48}$ One explanation for this may be the liberal legal climate that surrounds surrogacy in California, unlike many other US states. ${ }^{49}$ This will be discussed in more detail in the following section.

Third-party assisted conception, therefore, affects a significant number of adults and children in both the United Kingdom and United States. The social significance of issues surrounding ART has recently been highlighted in the media through various television documentaries such as 'I'm Pregnant with Their Baby'50 which charts the journey of three women who, out of altruism, agree to act as surrogates for couples they do not know and the problems they face when they have to give up their baby. This programme raises issues particularly relevant to the current study such as the desire for surrogate involvement following birth and the need to have clear legal regulation of parenthood. A further documentary, called 'Donor Mum: The Children I've Never Met', ${ }^{51}$ charts the journey of an egg donor as she tries to establish contact with her biological children, and her son, who was born through sperm donation, as he tries to track down his biological father. This programme emphasised the effect that decisions the parents make about having a child can have on that child in later life. This is relevant in relation to the current study because it suggests that some degree of donor involvement, or at least contact, might be beneficial for the child from an early stage in case they want to establish a relationship later on. This sentiment is reflected in the responses of a number of participants. ${ }^{52}$ Although the law has moved away from completely anonymous

\footnotetext{
${ }^{46}<$ http://www.surrogacyuk.org/> accessed 1 September 2011.

${ }^{47}<\mathrm{http}: / /$ www.councilforresponsiblegenetics.org/pageDocuments/KAEVEJ0A1M.pdf $>p ~ 7$ accessed 1 September 2011.

48 lbid. 10.

49 /bid. 29.

${ }^{50}<$ http://www.bbc.co.uk/programmes/b013y232> accessed 1 September 2011 and broadcast on BBC1 on 23 August 2011.

${ }^{51}<$ http://www.bbc.co.uk/programmes/b0146g40> accessed 1 September and broadcast on BBC 1 on 30 August 2011.

52Jane for example comments that "having conceived twins through egg donation, I have always found it a great loss to not have the option to access further information about the donor, aside from the bare minimum. So if an alternative had been available I certainly would have explored it.' See Chapter 4 for further discussion of this.
} 
donation in response to the future needs of the children, ${ }^{53}$ this is an area where the views of donor-conceived people have been traditionally underrepresented and further research should be conducted into this. ${ }^{54}$

Whilst assisted reproduction is highly topical and affects a growing number of people in the US and UK, the social, political and legal climate, particularly surrounding surrogacy, differs between E\&W and California, the two jurisdictions being compared in the present study. In California, surrogacy is quite a polarising issue particularly in relation to regulation of the industry as was highlight by the recent baby-selling scandal. ${ }^{55}$ Such strength of feeling has been engendered by the possibility of exploitation of surrogates as a result of the permissibility of commercial surrogacy. In E\&W, however, commercial surrogacy is illegal. ${ }^{56}$ Therefore, there is more ambivalence towards the whole issue of surrogacy, which is not as well developed as it is in California. It is on the backdrop of this social context that the legal rules must be understood and evaluated, as is consistent with the socio-legal approach.

\subsection{Legal Framework}

In E\&W, legal parenthood following assisted reproduction is governed by part 2 of the Human Fertilisation and Embryology Act $2008 .{ }^{57}$ Recognition of the legal mother of the child is a straightforward matter because it attaches to the woman who gives birth to the child. ${ }^{58}$ This merely applies the rule that existed at common law to the assisted reproduction context. ${ }^{59}$ Therefore, the act does not contemplate the possibility of a child being legally motherless. ${ }^{60} \mathrm{~A}$ child can only have one more parent, who can be either male, referred to as the father, or

\footnotetext{
53 Human Fertilisation and Embryology Authority (Disclosure of Donor Information) Regulations 2004. This enables a donor-conceived person over the age of 18 conceived following gamete or embryo donation taking place after April 2005 to request the identity of their donor from the HFEA. See Lucy Frith et al. 'UK Gamete Donors' Reflection on the Removal of Anonymity' (2007) 22(6) Human Reproduction 1675.

54l'm grateful to the participants who emphasized this point in their responses and comments on the study.

${ }^{55}<$ http://www.psychologytoday.com/blog/genetic-crossroads/201108/surrogacy-and-baby-

selling-another-fertility-industry-scandal> accessed 1 September 2011.

56 Surrogacy Arrangements Act 1985.

57 The 2008 Act or the Act.

58 Human Fertilisation and Embryology Act 2008, s 33(1)

${ }^{59}$ Ampthill Peerage Case [1977] AC 547 at p. 577.

60 In France, there is the possibility of having motherless children because women have the right to conceive anonymously. See Nadine Lefaucheur. 'French Tradition of Anonymous Birth: The Lines of Argument' (2004) 18 International Journal of Law, Policy and the Family 319.
} 
female, referred to as the child's second female parent. ${ }^{61}$ This second parent must meet certain conditions which revolve around his or her consent to be treated as a second parent, along with that of the mother.

In California, the Uniform Parentage Act ${ }^{62}$ defines who is considered a child's parent. In contrast to the 2008 Act, this was not specifically enacted to deal with the modern demands of assisted reproduction but rather enacts the federal uniform parentage act from 1973 designed primarily to deal with illegitimacy. Although the Uniform Parentage Act mentions gestation as a possible basis for recognising someone as the legal mother of the child, it does not consider gestation as determinative of the matter in the way that the 2008 Act does. ${ }^{63}$ Again, however, a child can only have two parents. The legislation itself contemplates the second parent as being a father. However, the courts have extended this to include a second female parent. ${ }^{64}$ There are a number of ways that a person can be recognised as a second parent including being registered on the birth certificate, accepting the child into his or her home or if there is a marriage between the second parent and mother. ${ }^{65}$

Whilst the courts in E\&W apply faithfully the rule that gestation demonstrates who the legal mother is, the courts in California have interpreted the Californian legislation to different effect. In Johnson $v$ Calvert, ${ }^{66}$ the Californian Supreme Court held that a gestational surrogate was not the legal mother of the child but rather the egg contributor who also intended to raise the child. This outcome was possible because of the wording of the legislative provision which did not state that gestation conclusively determines legal motherhood. ${ }^{67}$ In Johnson $v$ Calvert it seems to have been the combination of genetic connection and the intention to procreate that trumped the gestational surrogate's claim. This was extended in Buzzanca ${ }^{68}$ where a non-genetically related woman who had commissioned a gestational surrogate was considered to be the legal mother. In

61 Human Fertilisation and Embryology Act 2008 ss36 and 42.

62 Contained in Part 3, Division 12 of the Californian Family Code (UPA).

63 'between a child and the natural mother, [the parent child relationship] may be established by proof of her having given birth to the child, or under this part' Californian Family Code s 7610.

64 Elisa $B 37$ Cal 4 th 108.

65 Californian Family Code s 7611.

66 Johnson v Calvert (1993) 5 Cal 4th 84 . This case will be discussed further below.

67 See above $\mathrm{n} 62$.

68 In re Marriage of Buzzanca (1998) 72 Cal Rptr 2d, 282 
this case, the egg donor was anonymous and the gestational surrogate did not try to claim she was the legal mother.

\subsection{Definition of a Parent}

These different legal approaches lead to a discussion about the most suitable basis for conferring legal parenthood. The legislation in E\&W adopts a clear preference in favour of gestation as the basis for allocating legal motherhood over claims based on genetics or intention to procreate. Whilst the Californian legislation is not definitive on this matter, the courts have interpreted the legislation to mean that the claims of the gestational mother may be trumped by the genetic mother or even the mother who intended to procreate the child. It is not clear, however, how far this would stretch. For example the outcome may well be in favour of a traditional surrogate because she would be linked by gestation and genetics even though she had no intention to procreate the child and raise him or her as her own.

The issue now that warrants consideration is which of the potential bases for claiming parenthood deserves to win out. Biology has traditionally been the key component in determining who the mother is. Before the advent of assisted reproductive techniques there was no separation between genetic relation and gestation. Therefore, identifying the biological mother was a simple matter and it was she who was the legal mother of the child. Identifying the legal father was also a matter of biology. However because this was more difficult to determine than the biological mother, the legal father was the man who was married to the mother. This operated as a presumption that that man was the child's genetic father, which more recently can be rebutted with evidence to the contrary. ${ }^{69}$ Nevertheless, whether through the act of gestation or via a legal presumption, traditionally the law ascribed legal parenthood on the basis of biology.

This approach seems to accord with common sense in the context of traditional families. However, assisted reproduction provides an opportunity to reassess this because it creates a disconnect between biological relatedness and the intention to raise the child. Although ART does present an opportunity for reassessment of the primacy of biology in conferring legal parenthood, some still consider biology as the most suitable basis for this. Andrew Bainham has

69 Family Law Reform Act 1969, s 26. 
consistently argued that 'being a parent should turn on a presumed or actual genetic connection with the child'. ${ }^{70}$ This contention seems to be premised on the suggestion that to do otherwise would be to ignore or deny the biological truth of the matter and to 'distort and misrepresent kinship'. ${ }^{71}$

This approach has, however, not been adopted in the 2008 Act which recognises that two female parents can automatically be recognised as the parents of a child from birth. This clearly does not reflect the biological reality or truth of the conception of that child. It is for this reason that Therese Callus has criticised the reforms arguing that '[b]y recognising the status of two female parents, the child's identity is thrown into disarray because the recognition of two female parents conceals the necessary heterosexual element of human existence'. ${ }^{72}$ The importance of biology, evident in both Bainham and Callus's arguments, has received some support in judicial dicta. In $R e G$, for example, Lord Nicholls commented that 'in the ordinary way the rearing of a child by his or her biological parent can be expected to be in the child's best interests...I decry any tendency to diminish the significance of this factor.' 73 Indeed, Bainham relies on the judgment of Baroness Hale in that case to reinforce his point, stating that. '[w]e therefore have it on high authority that we should pause before equating the position of the biological parent with that of the lesbian partner' ${ }^{74}$

It seems questionable, however, whether the judgment in $R e G$ does give preference, to any great extent, to the claims of biological parents over competing claims. Baroness Hale explicitly recognises that a natural parent can be created in three ways: genetic parenthood, gestational parenthood or social/psychological parenthood. This gives the impression that a person can be considered the natural parent if one of these criteria are met even if the other two are not. Therefore the statement that 'the fact that CG is the natural mother of these children in every sense of that term, while raising no presumption in her

\footnotetext{
70 Andrew Bainham, 'Parentage, Parenthood and Parental Responsibility: Subtle, Elusive Yet Important Distinctions' in Andrew Bainham, Shelley Day Sclater and Martin Richards (eds), What is a parent? : a socio-legal analysis (Hart Pub., Oxford 1999) 27.

71 Andrew Bainham. 'Arguments about parentage' (2008) 67(2) Cambridge Law Journal 322, 341.

72 Thérèse Callus. 'First 'Designer Babies', Now À La Carte Parents' (2008) Family Law 143, 147.

73 Re G [2006] UKHL 43 [2] .

74 Andrew Bainham. 'Arguments about parentage' (2008) 67(2) Cambridge Law Journal 322, 340 .
} 
favour, is undoubtedly an important and significant factor in determining what will be best for them now and in the future', ${ }^{75}$ does not imply that biology was the decisive factor in finding in her favour over the claims of her former partner. The fact is that that CG had been the children's primary caregiver. Therefore, the House of Lords' judgment seems to be underpinned by the desire not to disrupt the children's lives rather than by any preference in favour of the biological parent.

In his argument supporting the primacy of biology, Bainham suggests that the values that govern the determination of parentage ought to be 'a commitment to truth, individual autonomy and priority for the interests of...the children'. ${ }^{76}$ Bainham suggests that the commitment to (biological) truth indicates that biological parentage is important and that a child has an interest in knowing who his or her biological parents are. It does not follow, as Bainham suggests, that the separation of biological and legal parentage following assisted reproduction is inconsistent with the principle of biological truth. These arguments perhaps support the case for a more accurate birth certificate, as some have argued for, ${ }^{77}$ which would record the biological as well as legal parents. It is, however, not the function of legal parenthood to record biological truth. In fact, legal parenthood would seem to serve a very different function within these families.

As Bainham and others have demonstrated, ${ }^{78}$ parental status is not about the bundle of rights and responsibilities required to raise a child. This is addressed by the concept of parental responsibility. Rather being a parent is what makes children and otherwise unrelated adults part of a family. ${ }^{79}$ Therefore when identifying the values that should underpin the determination of parenthood, the function of parental status needs to be borne in mind. If the function of parental

\footnotetext{
$75 \operatorname{Re}$ G [2006] UKHL 43 [44] .

76 Andrew Bainham. 'Arguments about parentage' (2008) 67(2) Cambridge Law Journal 322, 323.

77 Caroline Jones, 'Parents in Law: Subjective Impacts and Status Implications around the Use of Licensed Donor Insemination' in Alison Diduck and Katherine O'Donovan (eds), Feminist perspectives on family law (Routledge-Cavendish, London 2006) 94.

78 Andrew Bainham, 'Parentage, Parenthood and Parental Responsibility: Subtle, Elusive Yet Important Distinctions' in Andrew Bainham, Shelley Day Sclater and Martin Richards (eds), What is a parent? : a socio-legal analysis (Hart Pub., Oxford 1999) 33.

${ }^{79}$ See expert evidence set out in detail in Re $D$ [2006] EWHC 2 (Fam) [57].
} 
status is to create a family rather than to represent biological reality, biology loses its moral superiority as a determining factor for legal parenthood. ${ }^{80}$

As Bainham notes, the reforms instituted by HFEA 2008 'increase the circumstances....in which the social or intentional parent is treated in law as the parent'. ${ }^{81}$ This is evident in the way the 2008 Act allows a second female to automatically become a legal parent on the birth of the child or a second male to obtain a parental order to the same effect. Whilst this does nothing to promote the value of biological truth, it does give effect to the parties' intentions, which is a value worth protecting in itself. Hill argues that 'what is fundamental in rendering a biological progenitor a parent is not the biological tie itself, however, but the preconception intention and the preconception and postconception acts which the biological relation evinces'. ${ }^{82}$ Therefore rather than promoting biological truth, which after all could be a matter for the birth certificate, legal parentage, in the context of assisted reproduction, is trying to afford recognition to those who intend to care for and raise the child. That is not to say that intention should replace biological connection in the ordinary course of reproduction because conception in that context is not always intended. However, in the context of ART where intention plays such a large role, it is in fact the intention of the commissioning couple that instigates the whole process, it seems appropriate to afford it greater legal recognition than the claims of biology.

The role of intention and biology in determining legal parenthood is an issue that the Californian Supreme Court dealt with in Johnson $v$ Calvert ${ }^{83}$ and In re Buzzanca. ${ }^{84}$ In Johnson, the appellant (Ms Johnson) sought a declaration that she was the mother of a child, which she gave birth to on the understanding that the parents of the child would be the respondents (Mr and Mrs Calvert). In this case Johnson was a gestational surrogate and was implanted with an embryo created by Mr Calvert's Sperm and Mrs Calvert's egg. Therefore the court had to resolve whether Mrs Calvert or Ms Johnson was the legal mother of the child. The Californian Uniform Parentage Age, provides that gestation may be a

80 John Lawrence Hill. 'What Does it Mean to be a Parent--The Claims of Biology as the Basis for Parental Rights' (1991) 66 N Y U L Rev 353, 393.

81 Andrew Bainham. 'Arguments about parentage' (2008) 67(2) Cambridge Law Journal 334.

82 John Lawrence Hill. 'What Does it Mean to be a Parent--The Claims of Biology as the Basis

for Parental Rights' (1991) 66 N Y U L Rev 353, 414.

83 Johnson v Calvert (1993) 5 Cal 4th 84.

84 In re Marriage of Buzzanca (1998) 72 Cal Rptr 2d, 282 
ground for conferring legal motherhood, ${ }^{85}$ but does not make this a requirement. The court considered that a genetic relationship, such as that which existed between the child and Mrs Calvert, could be an alternative basis to gestation for conferring legal motherhood. In this case genetics and gestation pointed to two different women and the court felt that the intention of the parties was the best way to resolve the conflict, stating that:

....although the Act recognizes both genetic consanguinity and giving birth as means of establishing a mother and child relationship, when the two means do not coincide in one woman, she who intended to procreate the child - that is, she who intended to bring about the birth of a child that she intended to raise as her own - is the natural mother under California law. ${ }^{86}$

The importance of intention as a basis for determining legal parenthood was confirmed and extended in In re Buzzanca, which again concerned a gestational surrogacy but this time the child was not genetically related to the commissioning couple. The court extended the principle that a husband can become the lawful father of a child born through the artificial insemination of his wife by consenting to the procedure. They applied this principle to the commissioning couple concluding that they were the parents of the child because they had consented to the surrogacy arrangement as the intended parents. ${ }^{87}$

These judicial decisions may seem to indicate a strong preference in favour of parties' intentions determining legal parenthood in the context of assisted reproduction. However, the importance of these decisions is limited somewhat by the facts of the cases. In Johnson the court clearly used intention as a means of deciding between competing biological claims based on genetics and gestation. Although in Buzzanca the court extended this to apply to a situation where there were no competing biological claims, the parenthood was not contested by the surrogate and it was to avoid the conclusion that the child was legally parentless for the purposes of child support. It is uncertain whether intention alone would trump the genetic and gestational claim of a surrogate who asserted her claim to legal parenthood.

${ }^{85}$ Calfornian Family Code $s 7610$.

86 Johnson $v$ Calvert (1993) 5 Cal $4^{\text {th }} 84[6]-[7]$.

87 In re Marriage of Buzzanca (1998) 72 Cal Rptr 282. 
Schultz, however, argues in favour of a standalone notion of intention that would trump biological claims. She suggests that 'bargained-for intentions [should be] determinative of legal parenthood'. ${ }^{88}$ She restricts this to the context of ART because of the greater role that intention plays. In her argument, this increased focus on intention in parenthood reflects the greater degree of choice that adults exercise in their intimate lives as compared with the past. ${ }^{89}$ She suggests that the socially constructed nature of parenthood and the importance society attaches to parent-child relationships gives the role of intention in determining legal parenthood particular social significance. ${ }^{90} \mathrm{~A}$ manifestation of this, she suggests, is that if intention were afforded a central role in allocating legal parenthood, 'both the number and types of intention-based arrangements about parenthood would likely multiply'. ${ }^{91}$ This she suggests 'presses fundamental questions about whether parenthood is necessarily only a one man/one woman proposition'92

\subsection{Recognising Multiple Parents}

A diversity of parenting arrangements exist following ART, including those that intentionally involve multiple parents in raising the child. ${ }^{93}$ This leads on to a discussion of whether the law should recognise more than two legal parents, which, as in most jurisdictions, is not the case in California or in E\&W. This issue has received both academic and judicial discussion recently. Julie Wallbank argues that 'lesbian parents...adopt a wider range of strategies for parenting than is recognised as possible within the legal framework'. ${ }^{94}$ This is supported by Leanne Smith's research involving interviews with lesbian couples with children, which suggests that these alternative family structures that lesbian families adopt could be instructive in deciding how parenthood should be allocated. ${ }^{95}$

\footnotetext{
88 Marjorie Maguire Shultz. 'Reproductive Technology and Intent-Based Parenthood: An Opportunity for Gender Neutrality' (1990) Wis L Rev 297, 323.

89 Ibid 337.

90 lbid 321.

91 lbid 344.

92 lbid 344.

93 See Deborah Dempsey, 'Conceiving and Negotiating Reproductive Relationships: Lesbians and Gay Men Forming Families with Children' (2010) 44 Sociology 1145.

94 Julie A. Wallbank. 'Reconstructing the HFEA 1990: Is Blood Really Thicker Than Water?' (2004) Child and Family Law Quarterly 387, 388.

95 Leanne Smith. 'Is Three a Crowd: Lesbian Mothers' Perspectives on Parental Status in Law' (2006) 18(2) Child and Family Law Quarterly 231, 232.
} 
A good illustration of this is the family arrangement that was at issue in the Canadian case of $A A \vee B B .{ }^{96}$ The case concerned a female same-sex couple (A and $C$ ) who asked a male friend $(B)$ to be the biological father. Although $A$ and $C$ were to be the child's primary caregivers, they still wanted $B$ involved in the child's life. Under the Canadian legislation, A, the biological mother, and B were considered the legal parents of the child. All parties, however, wanted $C$ to be recognised as a legal parent but did not want to extinguish B's status, which adoption would have done. The Ontario Supreme Court considered that it was in the child's best interests that $C$ was recognised as a legal parent and the only way to do this without extinguishing the biological father's status was to recognise all three as legal parents, which the court did using their inherent jurisdiction. ${ }^{97}$ This is a novel case because it recognised the validity of the arrangement that the family had set up, namely that the child should have three legal parents, despite the fact that the legislation only contemplated two.

Whilst this has been the most progressive case, in that it is the only one that has made an outright declaration of parentage to three parties, there have been effectively similar, although perhaps more limited, outcomes in other jurisdictions. The U.S case of Shultz-Jacob, ${ }^{98}$ for example, concerned a similar co-parenting arrangement as $A A \vee B B$, which had broken down when the female same-sex couple separated. The Superior Court of Pennsylvania in that case recognised both the biological father and the mother's female partner as parents for the purposes of child support obligations. The court stopped short of declaring all three parties as legal parents of the child as the court did in $A A v$ $B B$. However, this is still a significant decision because the court recognises that the fact that all three were acting as de facto parents has, albeit limited, legal implications:

if fundamental fairness prevents Appellant, identified by law as a third party, from avoiding a support obligation arising from her status as a de facto parent, and she does not, in any event, attempt such an avoidance, does not the same principle operate similarly to estop Appellee Frampton, automatically recognized as

\footnotetext{
96 AA v BB 2007 ONCA 2.

97 Ibid 37.

98 Jacob vs Schultz-Jacob 2007 PA Super 118.
} 
the possessor of parental rights based on his biological parenthood, from disclaiming financial responsibility? ${ }^{99}$

The courts in E\&W have similarly recognised that the involvement of more than two adults in a parental capacity can have legal implications for all the parties, without having taken that extra step the Ontario court took of recognising each party as a legal parent. This is greatly facilitated by the possibility, contained in the Children Act of granting parental responsibility orders. ${ }^{100}$ Unlike parental status this need not be limited to two individuals. Parental responsibility is defined as 'all the rights, duties, powers, responsibilities and authority which by law a parent of a child has in relation to the child and his property'. ${ }^{101}$ The use of parental responsibility in co-parenting arrangements suggests a very functionbased, rather than status-based, approach to the issue. This is exemplified in the case of $\operatorname{Re} D,{ }^{102}$ which concerned a female same-sex couple (A and $C$ ) who advertised for a man (B) to have a child (D) with and subsequently be involved in the child's life. The biological mother $(A)$ and father $(B)$ are D's legal parents. However $\mathrm{C}$ has parental responsibility as a result of a joint residence order. B's contact with $D$ had been limited by a previous court order because of his disruptive influence on the family unit. The court was being asked to award $B$ parental responsibility, in addition to $A$ and $C$, on the basis of undertakings that $B$ would not interfere in Ds life in certain ways. The court was persuaded by these undertakings, which it made part of the order, and granted B parental responsibility in recognition of the important role that B played in D's life.

In $R e D$, the court were highly creative in their use of parental responsibility. As the court acknowledged, they were essentially conferring a status on the father as a result of the limitations they had placed on the order. ${ }^{103}$ This, however, does not seem to accord with the nature of parental responsibility, which is after all a function-based order. To limit parental responsibility in such a way in effect renders the concept devoid of meaning. It seems that what the father actually desired was to be recognised as a parent, which $A$ and $C$ refused to do because they believed this threatened their family unit. It seems that this could have been avoided if all three parties had been recognised as parents but perhaps

99 Ibid [20].

100 Children's Act 1989 s4.

101 Ibid s3.

$102 R e D$ [2006] EWHC 2 (Fam).

103 Ibid [91]. 
only $A$ and $C$ had been granted parental responsibility. In that way $B$ would feel valued as a part of the child's life and $A$ and $C$ would not feel threatened by B's presence. It is quite telling that they wanted $B$ to be considered the father but not a parent. In essence this suggests that they wanted $B$ to have a formal status in relation to $D$ but not to have the raft of rights and responsibilities in relation to $D$ that $A$ and $C$ had. Given that all parties wanted $B$ involved in D's life, this could be phrased to the effect that $A$ and $C$ wanted $B$ to be considered a parent alongside each of them but not to have parental responsibility as they did. As Dr Sturge commented in that case, ${ }^{104}$ perhaps it is more a case of not having the appropriate language for the situation. ${ }^{105}$

Some argue that parental responsibility is adequate to recognise social parents. ${ }^{106}$ However this underplays the importance of the status of parenthood. Lowe contends that the family unit should enjoy 'adequate and equal legal recognition' whatever form it takes. ${ }^{107}$ In the context of gay/lesbian co-parenting projects, 'adequate and equal legal recognition and protection' means granting full parental status to those who all parties intend to be social parents to the child. The reason for this is that being considered a parent is an important part of being considered a member of the family. ${ }^{108}$ As the court in $A A \vee B B$ acknowledged, being considered a parent is not only important in terms of its legal effects (e.g. the right to inherit) but also its extra-legal effects such as a feeling of connection between the social parent and child. ${ }^{109}$ Therefore, whilst Bainham's suggestion of merely allocating social parents parental responsibility may work on a pragmatic level, it does not allow gay and lesbian couples to create, through co-parenting projects, the type of family that would best reflect their underlying intentions.

\footnotetext{
104 Ibid [34].

105 See also Alison Diduck. "If only we can find the appropriate terms to use the issue will be solved': Law, identity and parenthood' (2007) 19(4) Child and Family Law Quarterly 1. 106 Andrew Bainham, 'Parentage, Parenthood and Parental Responsibility: Subtle, Elusive Yet Important Distinctions' in Andrew Bainham, Shelley Day Sclater and Martin Richards (eds), What is a parent? : a socio-legal analysis (Hart Pub., Oxford 1999) 27.

107 Nigel Lowe. 'A study into the rights and legal status of children being brought up in various forms of marital or non-marital partnerships and cohabitation: A Report for the attention of the Committee of Experts on Family Law of the Council of Europe ' (2009)

$<$ http://www.coe.int/t/DGHL/STANDARDSETTING/FAMILY/CJ-

FA\%20 $2008 \% 205 \% 20$ E\%2025\%2009\%2009.pdf> accessed 2 September 2011.

108 Caroline Jones, 'Parents in Law: Subjective Impacts and Status Implications around the Use of Licensed Donor Insemination' in Alison Diduck and Katherine O'Donovan (eds), Feminist perspectives on family law (Routledge-Cavendish, London 2006) 78.

$109 A A v B B$ (2007) ONCA 2 [35].
} 
Despite the increasing importance of equality discourse that has led to an increased acceptance of same-sex relationships, society's fundamental assumptions in relation to the sexual family remain largely unchanged. As Fineman highlights:

But these reforms merely reinforce the idea of the sexual family. By duplicating the privileged form, alternative relationships merely affirm the centrality of sexuality to the fundamental ordering of society and the nature of intimacy. ${ }^{110}$

The suggestion here is that alternative families, although increasingly recognised in law, are having to conform to a legal framework that was not designed with them in mind and that operates on the basis of assumptions that may be fundamentally at odds with the type of families they are trying to create, including co-parenting arrangements.

\subsection{Conclusion}

Overall, therefore, the legislative framework in E\&W and California seems to pursue the same ends, namely that the woman who gives birth to the child is the legal mother within a two-parent model where the father is such through biology or consent to ART treatment. Despite this, the courts in both jurisdictions have been creative in the allocation of parenthood to take into account the intentions of the parties. This has had the effect in E\&W that thirdparty donors, in addition to the legal parents, perform certain parental functions without being afforded full recognition as a legal parent through the use of parental responsibility orders. This adopts a very function-based approach to the allocation of parenthood. However, this overlooks the considerable significance the status of parent has in the formation of alternative family forms.

It seems that the Californian courts, by focussing on the intention of the parties, have laid the foundation for the possibility of recognising multiple-parent families in the way that the Canadian courts already have. To a certain extent this approach has, in effect, been adopted by the courts of E\&W through the use of parental responsibility orders. However, this fundamentally fails to recognise the importance of parental status in the creation of alternative family forms.

110 Martha Albertson Fineman, The neutered mother, the sexual family, and other twentieth century tragedies (Routledge, New York ; London 1995) 143 


\section{Methodology}

\subsection{Introduction}

The aim of the empirical research in this project was to explore why people hold the views they do about involving a gamete donor or surrogate in the lives of their children who were born using third-party assisted reproduction. More specifically the research project was designed to investigate the following research questions: what level of donor/surrogate involvement do people who have received ART desire? What are the reasons for this? What level of legal recognition would they afford the donor/surrogate? The intention was to gain a detailed understanding of the reasons and values that underpin attitudes towards donor/surrogate involvement in order to assess whether these are reflected in the legal regulation of parenthood following assisted reproduction.

In order to address these research questions fully, it seemed appropriate to adopt a mixed methods approach. It was felt that the topic would benefit from combining a quantitative survey gathering generalisable data on social attitudes followed by an in-depth qualitative exploration of the motivations behind these views in order to provide a holistic view of the issue. This seems well suited to the research topic because, whilst a quantitative study can identify trends in attitudes, it is unlikely to be able to tease out the complex reasons that influence people's attitudes in relation to this highly sensitive topic. ${ }^{111}$ Therefore, an indepth qualitative study of a smaller group of individuals seemed appropriate to complement the quantitative study. This has been done to good effect in other socio-legal studies. ${ }^{112}$ Although this was the original intention, the small sample size that was achieved, and is discussed in more detail below, meant that the results of the quantitative study could not be more broadly generalised as had been hoped if there had been more respondents. As a result of the iterative approach this study adopted between data collection and research design, ${ }^{113}$ the latter was able to be adapted to accommodate this in response to the

\footnotetext{
${ }^{111}$ See Alan Bryman, Social research methods (3rd edn Oxford University Press, Oxford 2008) 612.

${ }^{112}$ See for example Anne Barlow, Carol Burgoyne and Janet Smithson. 'The Living Together Campaign - An investigation of its impact on legally aware cohabitants' (2007) Research Series 5/07 <http://www.justice.gov.uk/docs/living-together-research-report.pdf > accessed 5 September 2011.

${ }^{113}$ As is accepted as good practice in this type of study. See Alan Bryman, Social research methods (3rd edn Oxford University Press, Oxford 2008) 12.
} 
emerging empirical data. In the end, the study did employ both quantitative and qualitative techniques to good effect. The quantitative survey served the dual purpose of providing a sampling frame for the interviews and also as an aid to forming the interview guide. This is seen as 'one of the chief ways in which quantitative research can prepare the ground for qualitative research'114 and is discussed in more detail below. Although the scale of the study limits its potential impact, it did allow some important conclusions to be drawn. It also raised and clarified important questions that should be explored in further research, especially in relation to groups less represented in the achieved sample such as same-sex couples.

It is important to be clear about the nature of the research and the knowledge produced by it. Despite the inclusion of both quantitative and qualitative techniques, this does not presuppose a particular epistemological outlook. This study rather attempts to adopt a research strategy that is best suited to answering the present research questions. ${ }^{115}$ The study does not attempt to collect scientifically verifiable data on the nature of a single social reality. It rather acknowledges the multiple perspectives of participants as they construct and interpret their social environment. ${ }^{116}$ Therefore, this study is influenced by social constructivism, which is premised on the notion that individuals create their own subjective meanings based on interaction with others and the various norms that operate in people's lives. ${ }^{117}$ Rather than impose predefined theory on the research data, the study has attempted to develop and generate theory inductively based on the data gathered from research participants. That is not to say that data collection was approached with no preconceived theoretical framework. Concepts were derived from the literature review (e.g. tension between social and biological conceptions of parenthood, idea of entering coparenting arrangements) and used as sensitising concepts to inform the data

\footnotetext{
114 Alan Bryman, Social research methods (3rd edn Oxford University Press, Oxford 2008) 619. For an example of how this was employed in a study on criminal offenders see Janet Jamieson, 'Negotiating Danger in Fieldwork on Crime: A Researcher's Tale' in Stephanie Linkogle and Geraldine Lee-Treweek (eds), Danger in the field : risk and ethics in social research (Routledge, London 2000) 212.

${ }^{115}$ See Hope Olsen. 'Quantitative "Versus" Qualitative Research: The Wrong Question' $<$ http://www.ualberta.ca/dept/slis/cais/olson.htm> accessed 19 April 2011 accessed 4 September 2011.

${ }^{116}$ See Alfred Schutz, The problem of social reality (Nijhoff, The Hague 1962) 59.

117 John W. Creswell, Qualitative inquiry and research design : choosing among five traditions (Sage Publications, Thousand Oaks, Calif. 1998) 21.
} 
collection. ${ }^{118}$ However, in order to stand alongside the categories developed through data analysis, these sensitising concepts had to be reflected in the data gathered and gain purchase in that way rather than being imposed on the data. ${ }^{119}$

In order to generate theory from data, this study has adopted a grounded theory approach. This has traditionally been associated with a positivist understanding of the social world. ${ }^{120}$ However, recently a constructivist version of grounded theory has been developed. ${ }^{121}$ This draws on the traditional conception of grounded theory, ${ }^{122}$ in the sense that there is an inductive relationship between data and theory, the latter being generated on the basis of careful coding of the data. However, rather than doing this in order to ensure a rigorous representation of objective reality, the study emphasised the importance of the interpretations that both the participants and researcher brings to the data. In this sense researcher reflexivity is important. ${ }^{123}$ The values that the researcher brings to the research can be as important as those that the research participants bring. ${ }^{124}$ Therefore the data that were collected was analysed on the basis of an interpretative theoretical framework that was explicit about the researcher's critical stance to the current state of the law.

\subsection{Data Collection}

\section{Sample}

This study sought to reflect a range of views of individuals who had made use of third party assisted reproduction because they were likely to have considered

118 Barney G. Glaser, Theoretical sensitivity : advances in the methodology of grounded theory (Sociology Press, Mill Valley, Calif. 1978) 164. See also Glen Bowen. 'Grounded Theory and Sensitizing Concepts' (2006) 5(3) International Journal of Qualitative Methods 12.

119 Kathy Charmaz, Constructing grounded theory (Sage Publications, Thousand Oaks, Calif. 2006) 16 - 17.

120 Barney G. Glaser and Anselm L. Strauss, The discovery of grounded theory : strategies for qualitive research (Observations, Weidenfeld \& Nicolson, London 1968) 271.

121 See Kathy Charmaz, 'Grounded Theory in the 21st Century: Applications for Advancing Social Justice Studies' in Norman K. Denzin and Yvonna S. Lincoln (eds), The SAGE handbook of qualitative research (3rd edn Sage Publications, Thousand Oaks, Calif. 2005) 1210 and Kathy Charmaz, Constructing grounded theory (Sage Publications, Thousand Oaks, Calif. 2006). ${ }_{122}$ See Juliet M. Corbin and Anselm L. Strauss, Basics of qualitative research : techniques and procedures for developing grounded theory (3rd edn Sage Publications, Inc, Thousand Oaks, Calif. 2008) 379.

${ }^{123}$ For more on this see Samia Bano, "Standpoint', 'Difference' and Feminist Research' in Reza Banakar and Max Travers (eds), Theory and method in socio-legal research (Oñati international series in law and society, Hart Publishing, Oxford 2005).

124 Alan Bryman, Social research methods (3rd edn Oxford University Press, Oxford 2008) 24 26. 
issues surrounding donor/surrogate involvement. In order to obtain such a purposive sample, the project was advertised, with a link to an online questionnaire, on infertility and assisted reproduction online support groups both in the UK and US. In addition, key institutional contacts were identified within various support groups in the UK and both support groups and surrogacy agencies in the US in order to disseminate the call for participants more widely.

The sample size that this project sought was between 15 - 20 respondents to the questionnaire in each jurisdiction with approximately one third consenting to a follow up interview. Ideally the sample would have a fairly even gender balance with the views of participants in both same-sex and different-sex relationships being represented. It soon became clear, however, that the majority of respondents were the female spouse of a (heterosexual) married couple. This is unsurprising given that females tend to participate in social research more readily ${ }^{125}$ and heterosexual couples form the bulk of patients treated using ART.126 This suggests that men and same-sex couples who have made use of ART are a harder to access groups. This study has adopted an iterative approach between data collection and research design, the latter of which has evolved in response to the empirical data. Therefore, in order to try to gain access to same-sex ART users, contact was made with LGBT charities and support groups such as Stonewall and parenting support groups, in order to try to recruit participants. In addition to this snowball sampling was used in order to increase the response rate whereby current participants were asked to pass on information of the study to anybody they know who might be interested in participating. ${ }^{127}$

Due to the constrained time frame of eight weeks in which this study could be conducted, a sample of twenty responses to the online questionnaire was achieved, across both California and E\&W. Of these nine participants agreed to be interviewed further by telephone. This included two males, two females in a

\footnotetext{
125 Linda Sacks et al. 'Assessing Response Rates and Non-Response Bias in Web and Paper Surveys' (2003) 44(4) Research in Higher Education 409, 424

126 According to HFEA Statistics, just over $2 \%$ of those treated using IVF or donor insemination in 2006 were same-sex couples. See

$<$ http://www.hfea.gov.uk/docs/Latest long term data analysis report 91-06.pdf.pdf $>$ accessed 5 September 2011.

127 See Charles Teddlie and Fen Yu, 'Mixed Method Sampling: A Typology with Examples' (2007) 1(1) Journal of Mixed Methods Research 77. See also Jenifer Mason, Qualitative Researching (Sage, London 2002) 140.
} 
same-sex relationship and the remainder of respondents to the online questionnaire were heterosexual females. Unexpectedly, two of the participants who completed the questionnaire and agreed to take part in the follow-up interview were from Canada. Given the legal developments in Canada, the research design was modified to include their participation. Therefore the data from these participants were analysed with the California data given the geographic proximity and also the Canadian legal position is more closely aligned with California than E\&W. Although the sample that was achieved was not ideal, the valuable data gathered from the participants captures a range of views and does allow the study, at the very least, to pose insightful questions that deserve to be researched further. Further research in this area, for example, might meaningfully attempt to access the views of more same-sex couples and male partners on this issue. However, creative sampling strategies will have to be used for a more sustained period in order to access this difficult-to-access group, as this study has shown. ${ }^{128}$

\section{Data Collection Instruments}

In the first phase of the study, online questionnaires were used to identify participants' attitudes towards donor/surrogate involvement. The online questionnaire ${ }^{129}$ was considered to be the most effective means of collecting data from as large a group of respondents as possible. It was also seen as a flexible instrument that facilitated the creation of likert scales and the use of filter questions. ${ }^{130}$ Although the questionnaires did collect significant data, they were mainly used as a sampling frame for the semi-structured interviews and also as a means of developing follow-up questions to explore people's views and experiences in more depth. In light of this, a representative sample was not sought because the findings were not intended to be generalisable to the population at large but rather to provide a snapshot of people's experiences and views.

In order to elicit participants' views to particular family arrangements, vignettes were used. These presented situations involving donor and surrogate

\footnotetext{
${ }^{128}$ After the survey was taken down there were a number of participants who offered to take part. Therefore, a longer sample recruitment period would be desirable in future research. 129 See appendix 1

130 Alan Bryman, Social research methods (3rd edn Oxford University Press, Oxford 2008) 645.
} 
involvement as well as the legal consequences of this. ${ }^{131}$ As Hughes highlights, vignettes are a particularly useful way of discussing sensitive topics because they present the question in a less direct and threatening way. ${ }^{132}$ Vignettes are advantageous not only in eliciting normative responses, ${ }^{133}$ which in this context might take the form of ascertaining what rights and responsibilities donors/surrogates should have, but they also help interviewees to contextualise responses. ${ }^{134}$ This was important in the current research project, as it was necessary to illustrate how the law operates in a given context, in order to ensure that participants understood the legal situation. What is more, the use of vignettes helped to make the scenario under discussion more concrete.

The questionnaire was piloted on staff and $\mathrm{PhD}$ students in the School of Law at the University of Exeter some of whom were parents and though likely to be able to contextualise their views appropriately. An adapted version of the pilot questionnaire was then sent to institutional contacts within a Californian surrogacy agency in order to ensure that it was suitable for a Californian audience. Only minor changes were suggested to the questionnaire and interview guide. Therefore, it was felt that the perspective gathered during piloting was potentially significant comparator data for the study. This data were therefore analysed and included in the discussion. However, it has been made clear that these are the views of the educated layperson who have no actual experience with assisted reproduction technology. This however provides an interesting comparison with the actual sample of participants and is used as a means of enhancing the overall analysis where only a relatively low response rate from sought after participants was achievable in the timeframe imposed for this study.

During the second phase of the project semi-structured interviews were conducted with all the participants who had agreed to a follow-up interview. Such interviews have been used to good effect in previous feminist research which has drawn on social constructivism ${ }^{135}$ and was seen as a good means of

\footnotetext{
131 See questions 1, 2, 4, 5 and 7 in appendix 1.

132 Rhidian Hughes. 'Considering the Vignette Technique and its Application to a Study of Drug Injecting and HIV Risk and Safer Behaviour' (1998) 20(3) Sociology of Health and IIIness 381.

133 Alan Bryman, Social research methods (3rd edn Oxford University Press, Oxford 2008) 245.

134 Christine Barter and Emma Renold. 'The use of vignettes in qualitative research' (1999) 25 Social Research Update .

135 See e.g. Mary Allen. 'Violence and voice: using a feminist constructivist grounded theory to explore women's resistance to abuse' (2011) 11 Qualitative Research 23.
} 
exploring in-depth the experiences of research participants. ${ }^{136}$ Semi-structured interviews are particularly suitable in the context of a research project influenced by constructivism because they can be very participant-driven ${ }^{137}$ and they allow participants to explore issues in their own way without having a structure artificially imposed on them by the researcher. ${ }^{138}$ Focus groups were considered. However, given the geographical spread of participants both in E\&W and California, this did not seem a feasible option. In addition to this, semi-structured interviews are particularly well-suited to discussing personal decision making of the type explored in this study, especially when employing the vignette technique. ${ }^{139}$

The interview guide ${ }^{140}$ included open-ended questions which allowed the participants to expand on their answers. Possible prompting questions were also included in the schedule to ensure that participant's opinions were solicited on specific issues if they did not volunteer that information. Interview transcripts were analysed shortly after the interview, as described in the data analysis section. Themes that began to emerge in earlier interviews were presented to participants in subsequent interviews for comment e.g. donor involvement potentially might be more desirable in same-sex couples. In this way new emerging ideas and themes could be explored more fully.

Due to the sample's geographic spread, the majority of interviews were conducted over the telephone. This has the disadvantage that non-verbal cues and body language cannot be observed which may have been useful. However, this is outweighed by the travel costs that are avoided by telephone interviewing and the likelihood that a telephone interview is a less distressing environment to answer sensitive questions than a face-to-face interview. ${ }^{141}$ All were digitally recorded and then transcribed. Although the initial intention was to conduct all the interviews over the telephone, the demands of empirical research often require rethinking methodology as a result of practical considerations. Some respondents were currently undergoing treatment cycles and indicated that they were unable to devote the time to a telephone interview but were happy to be

136 Alan Bryman, Social research methods (3rd edn Oxford University Press, Oxford 2008) 437.

137 Janet A.E. Creelman and Roma M. Harris. 'Coming Out: The Information Needs of Lesbians' (1993) 10(3) Collection Building 37.

138 Alan Bryman, Social research methods (3rd edn Oxford University Press, Oxford 2008) 463.

139 lbid 448.

140 See appendix 2.

141 Alan Bryman, Social research methods (3rd edn Oxford University Press, Oxford 2008) 447. 
interviewed via e-mail. Therefore telephone interviews were combined with email interviews, which have previously been done to good effect in qualitative research. ${ }^{142}$ Furthermore, there is evidence to suggest that there is little difference in the quality of responses between telephone and face-to-face interviewing. ${ }^{143}$ To a large extent this was true in the present study but there were some additional difficulties that had to be overcome in relation to the email interviews.

One concern with asynchronous online interviewing such as this is that it can be quite protracted and respondents may drop out along the way. ${ }^{144}$ As it turned out, the respondents that requested e-mail interviews were highly motivated and passionate about the subject. Therefore the e-mail exchanges proved a rich source of data because the participants were able give more considered answers although there sometimes were quite long delays between responses. However, it was harder to elicit responses to hypothetical situations via e-mail than over the telephone because participants would often bring their responses back to their own situation. Despite suggestions that it is harder to maintain rapport with participants in online interviews compared to face-to-face interviews, ${ }^{145}$ there was a real sense of mutual trust developed in the e-mail exchanges that made participants feel comfortable expanding on their answers to sensitive questions in detail. ${ }^{146}$ This also meant that the interviewer could come back to certain points that were raised after having considered them and seek further elaboration. This was facilitated by the decision to send questions in small batches rather than all at once. ${ }^{147}$ These benefits were seen as outweighing the various drawbacks.

\subsection{Data Analysis}

The information from the questionnaire was never intended to provide statistically representative data that could be generalised within a quantitative

\footnotetext{
142 Sarah Nettleton and others, 'The Reality of Virtual Social Support' in Steve Woolgar (ed), Virtual society? : technology, cyberbole, reality (Oxford University Press, Oxford 2002) 180.

143 J. E. Sturges and K. J. Hanrahan. 'Comparing Telephone and Face-to-Face Qualitative Interviewing: A Research Note' (2004) 4 Qualitative Research 107, 115.

144 Alan Bryman, Social research methods (3rd edn Oxford University Press, Oxford 2008) 642.

145 See Carolyn Folkman Curasi. 'A critical exploration of face-to-face interviewing vs. computermediated interviewing' (2001) 43(4) International Journal of Market Research 361.

146 Chris Mann and Fiona Stewart, Internet Communication and Qualitative Research: $A$ Handbook for Researching Online (Sage, London 2000) 138 - 9.

147 R. Bampton and Cowton C.J. 'The E-Interview' (2002) 3(2) Forum Qualitative Social

Research 9 accessed 15 August 2011.
} 
framework. Despite this, basic descriptive statistical analyses were carried out on the results from the questionnaire in order to indicate prevailing views within the sample and its demographics. This has been used to indicate general trends in attitudes although a more diverse sample may result in a broader range of views and that further research on this would be appropriate. The main purpose of the questionnaire, however, was to provide the basis for further data collection in the semi-structured interviews. Therefore the free text data in the questionnaire was coded in order to identify certain basic themes such as 'threatens family unit' or 'who am I to judge?'. These were then reflected in the interview questions to tease out each participant's views in relation to these themes. In this way there was an iterative relationship between data analysis and collection with the former continuing alongside and informing subsequent data collection, as is consistent with grounded theory methodology. ${ }^{148}$

In relation to the interviews, these were transcribed and systematically coded line-by-line, in accordance with the loose precepts of grounded theory, in an attempt to code only what was represented in the data rather than introducing predefined theory. This allowed emergent 'in vivo' concepts to appear. ${ }^{149}$ Whilst this was the aim, it is important to acknowledge that data analysis is conducted through the lens of the researcher's own interpretations and as such does not attempt to be completely value-free. ${ }^{150}$ This coding was used as a platform to subsequently develop more abstract themes. ${ }^{151}$ Initial 'in vivo' codes, namely codes developed from the phrases used in the participants responses, that emerged in early interviews were presented to participants in subsequent interviews for comment. This allowed the development of selective codes and the emergence of broad themes. ${ }^{152}$ For example early 'in vivo' codes in relation to co-parenting included 'what's the point?'; 'no additional benefit'; 'It's fine if it

\footnotetext{
148 Kathy Charmaz, Constructing grounded theory (Sage Publications, Thousand Oaks, Calif. 2006) 23 -24.

149 Juliet M. Corbin and Anselm L. Strauss, Basics of qualitative research : techniques and procedures for developing grounded theory (3rd edn Sage Publications, Inc, Thousand Oaks, Calif. 2008) 105.

150 Mary Allen. 'Violence and voice: using a feminist constructivist grounded theory to explore women's resistance to abuse' (2011) 11 Qualitative Research 23, 34.

151 Kathy Charmaz, 'Grounded Theory in the 21st Century: Applications for Advancing Social Justice Studies' in Norman K. Denzin and Yvonna S. Lincoln (eds), The SAGE handbook of qualitative research (3rd edn Sage Publications, Thousand Oaks, Calif. 2005) 517.

152 Kathy Charmaz, 'Grounded Theory: Objectivist and Constructivist Methods' in Norman K. Denzin and Yvonna S. Lincoln (eds), The SAGE handbook of qualitative research (2nd edn Sage Publications, Thousand Oaks, Calif. 2000) 515.
} 
works for them'. This allowed for the development of a broader theme, namely the distinction between personal preferences and external preferences. ${ }^{153}$

\subsection{Ethical Considerations ${ }^{154}$}

Fully informed consent was achieved through an online information sheet explaining the voluntary nature of the project, including the ability to withdraw at any time, and consent form, which had to be accepted before completing the questionnaire. ${ }^{155}$ Confidentiality was ensured, as far as possible, by the use of pseudonyms when discussing the empirical data in order to protect participants' identities. ${ }^{156}$ In terms of data protection, interview transcripts and the results of the questionnaire were anonymised and securely stored, separately from participants' details. ${ }^{157}$

\footnotetext{
${ }^{153}$ See chapter 5 for more detailed discussion of these themes.

154 The research was guided by the Socio-Legal Studies Association (SLSA) Statement of Principles of Ethical Research Practice (2009)

155 See appendix 1.

${ }^{156}$ See appendix 3 for a table of the jurisdiction, which each participant came from in order to facilitate easy comparison.

157 This was done in compliance with the Data Protection Act 1998 and the University of Exeter, School of Law's Ethical Checklist.
} 


\section{Donor/Surrogate Involvement}

\subsection{Introduction}

This study has adopted as its starting point the premise that co-parenting arrangements ${ }^{158}$ exist in the context of ART and that there is a lack of uniformity in their legal recognition. ${ }^{159}$ The form such legal regulation should take is a complex and multi-faceted issue that would require detailed research into the various forms of co-parenting arrangements that exist as well as consideration of other legal and ethical factors. ${ }^{160}$ The present study does not suggest that legal regulation should depend solely on the views of the people concerned. Given the diversity of legal approaches to such arrangements, however, it is important to canvass opinion, from a number of jurisdictions, on a topic of such social significance as this. ${ }^{161}$ Despite certain limitations in the sample that was achieved, ${ }^{162}$ the study has gathered a range of views on donor/surrogate involvement, from participants in both California and E\&W who had made use of ART and therefore were particularly concerned by these issues. The current chapter will explore views in relation to donor/surrogate involvement and the motivations behind this, in response to the first two research questions. The following chapter will then consider perceptions in relation to the adequacy of legal recognition, in response to the final research question. ${ }^{163}$

\subsection{Co-parenting}

Although the notion of the existence of co-parenting arrangements, derived from the literature, underpins this study, no assumption is made about the desirability of such arrangements. The study attempts to assess the viability/desirability of

\footnotetext{
158 See Deborah Dempsey, 'Conceiving and Negotiating Reproductive Relationships: Lesbians and Gay Men Forming Families with Children' (2010) 44 Sociology 1145 for a discussion of the different types of arrangements that exist. In this study, co-parenting refers to a significant degree of donor/surrogate involvement in the child's life.

159 The existence of various forms of co-parenting arrangements following ART and the diversity of approaches that exist to their legal recognition is derived from case law in a number of jurisdictions. For a more detailed discussion of this see Chapter 2: Literature review pp $22-26$. ${ }^{160} \mathrm{~A}$ detailed consideration of this is beyond the scope of the present study. Further research, however, would benefit from considering such ethical and legal issues as the best interest of the child versus the legal equality of the parents.

${ }^{161}$ For more detailed discussion of the social significance of this area of research see Chapter 2: Literature Review pp $13-15$.

162 The sample and its limitations are discussed more fully in Chapter 3: Methodology at pp $30-$ 31

163 The aim and research questions of this study are set out more fully in Chapter 3 :

Methodology at $p 27$.
} 
these arrangements for the participants of this study without assuming their existence. Therefore, whilst the concept of co-parenting arrangements is used to structure the questions in this study, this is not externally imposed on them but rather gains purchase in the research through participants' own use of the concept, as is consistent with grounded theory methodology. ${ }^{164}$

In order to achieve this, one of the aims of this study was to investigate the level of donor and surrogate involvement that individuals who had made use of thirdparty assisted reproduction would want in their children's lives. This was explored in the online questionnaire, where participants were given various options about how much they would want a donor, traditional surrogate and gestational surrogate involved. ${ }^{165}$ The results of these questions are displayed graphically below to allow for easy comparison between the jurisdictions (see figures 1 - 3). ${ }^{166}$ In each of the graphs below the views of the pilot group are represented in order to provide an interesting comparison between individuals who approach this from a purely theoretical point of view and those who have actually been involved in the process. ${ }^{167}$

Figure 1: Donor Involvement

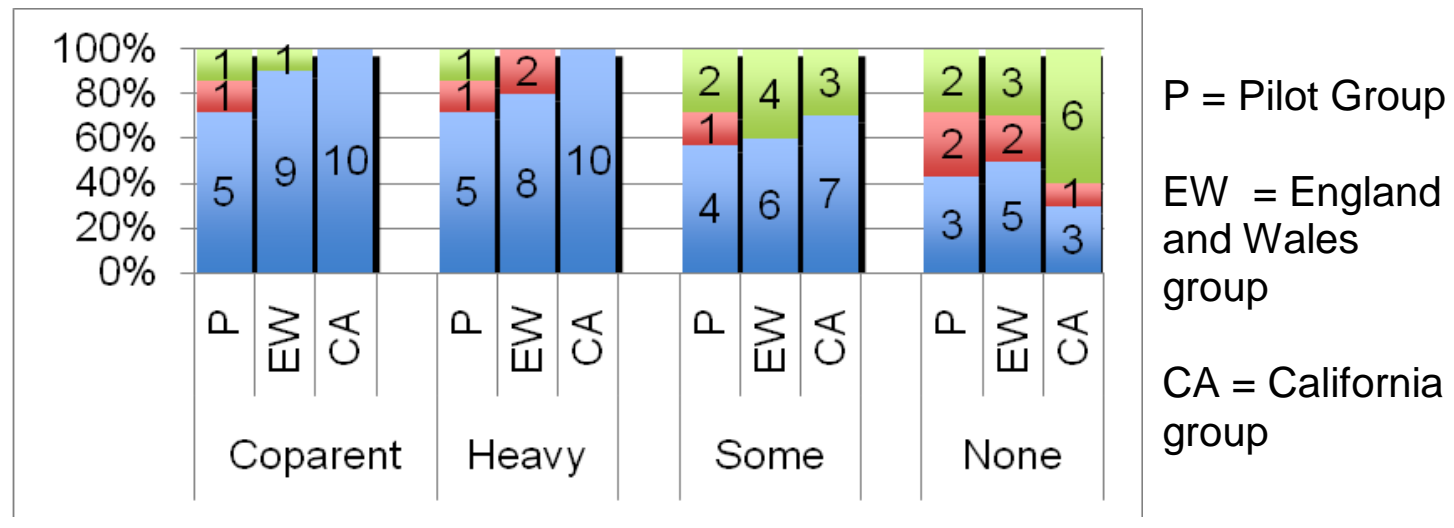

\footnotetext{
164 For a more detailed discussion of this see Chapter 3: Methodology pp $27-29$.

165 See questions 3, 6 and 8 in appendix 1.

166 In order to facilitate graphical representation, strongly agree and agree are represented as one variable (agree), and strongly disagree and disagree are represented as disagree.

${ }^{167}$ This was not possible in relation to gestational surrogates because this question was introduced after the piloting phase of the study.
} 
Figure 2: Traditional Surrogate Involvement

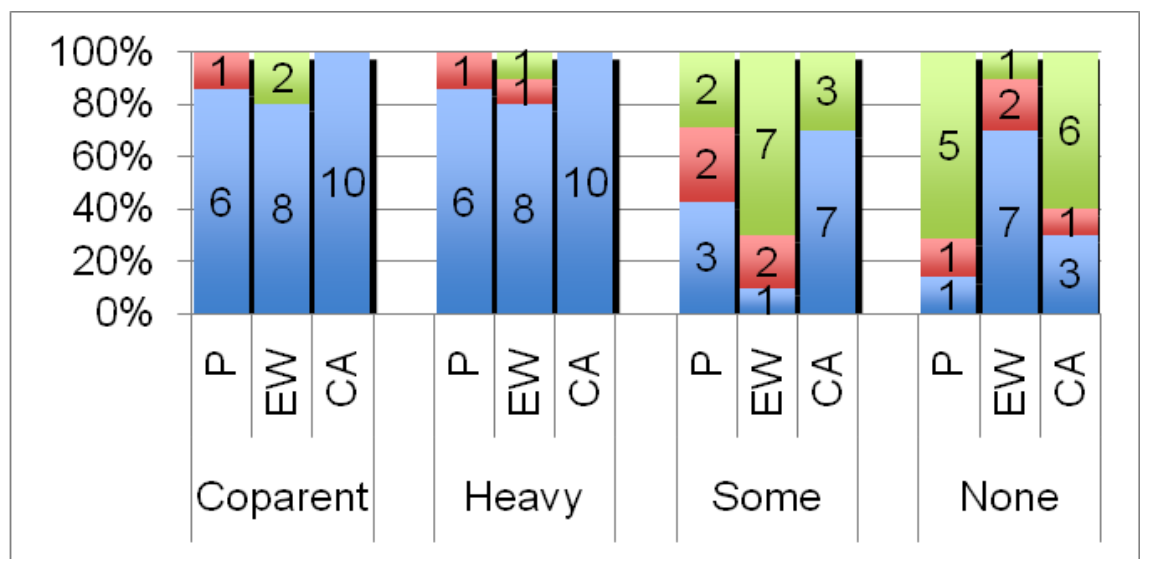

Figure 3: Gestational Surrogate Involvement

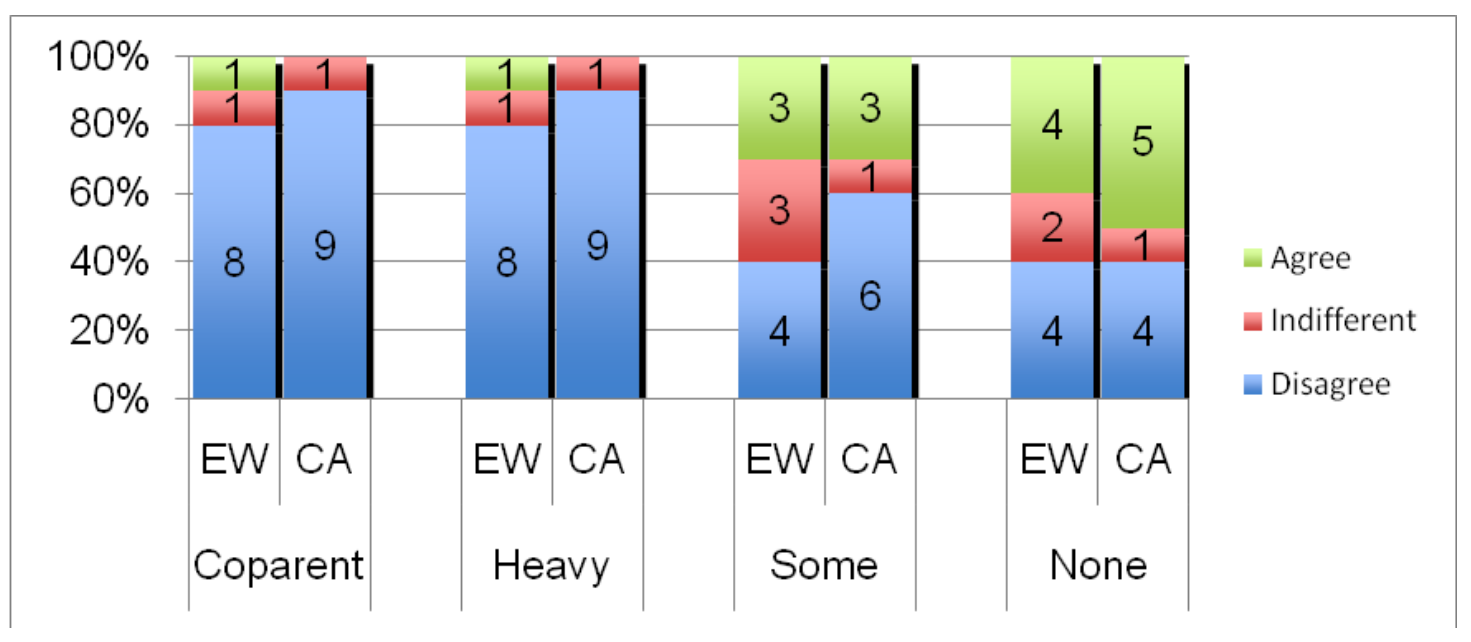

From the graphs, it is interesting to note that there is a broad consensus between all three groups (pilot group, participants from E\&W and participants from California) that they would not consider engaging in a co-parenting arrangement. One explanation for this is the seeming rarity of this type of intentional co-parenting arrangement amongst heterosexual couples. ${ }^{168}$ Therefore, perhaps it is to be expected that the majority of participants would resist this type of arrangement. As Dianne, a single woman from E\&W, commented during the interview:

Traditionally and because of my upbringing in the UK, I'm not used to the 'having more than two parents' scenario. So to me it seems

\footnotetext{
168 Whilst there is little statistical information about this, studies have suggested that these types of arrangements are specifically sought within the gay community to an extent that is not present amongst heterosexual couples. See for example Susan Hogben and Justine Coupland 'Egg Seeks Sperm. End of Story...? Articulating Gay Parenting in Small Ads for Reproductive Partners' (2000) 11(4) Discourse and Society 459, 462
} 
unfamiliar. That might influence why I'm quite against the threeway parenting system.

This view, that co-parenting is 'not for us', seems to be reflected across all the groups. This may, however, be a reflection of the demographics of the groups, in that the majority of the participants were married heterosexuals, to whom such an arrangement may not appeal perhaps because of the desire to perpetuate the public assumption that the child was conceived naturally in a way that is not possible for same-sex couples. ${ }^{169}$ As Connie, a married woman from E\&W with two daughters born using donor sperm, remarked, 'I couldn't really see heterosexual couples wanting to enter into that kind of agreement. It would be like bringing someone else into your marriage really'. This is a comment echoed by a number of participants. For example, Annabel, a married woman from California with one child born using IVF with her and her husband's own embryo, commented that 'heterosexual couples are maybe more on the traditional (we're not going to do that. That's crazy thinking)...'

At this stage of the analysis, the weight of the evidence from participants suggests that heterosexual couples are not likely to consider entering into a coparenting arrangement with the donor/surrogate for themselves perhaps because of traditional thinking or perhaps because they don't see any need to do so. As Eric, a single man from E\&W highlighted, 'if the child has got a father and a mother in a couple...I don't so much see the need for an extra father in that child's life'. However, this does not necessarily reflect the views of all heterosexual couples. There may well be heterosexual couples that would want to engage in some sort of co-parenting project. As Carmen, a married woman from California currently undergoing treatment with donor eggs, noted:

I think it's more of a possibility to have that kind of relationship if it's a known donor and same if it is a lesbian or a heterosexual couple, if they know the donor and the donor is someone very close to them or in their family then I think there is a natural relationship that is already established because they are already in each other's lives.

In Carmen's opinion it has less to do with whether it is a same-sex or differentsex couple undergoing treatment but rather whether they are involving a friend

${ }^{169}$ As Eric commented, 'it's more about pretending, carrying on as though the social parents are the real parents.' 
or family member in that process. This point seems to be crucial because none of the participants were actually using a friend as donor or surrogate. All of the participants for whom this was relevant had gone down the route of using a previously unknown donor or surrogate.

\subsection{Known Donor Involvement}

The fact that none of these participants had gone down the route of using a known donor/surrogate is significant because in many cases they had considered this option but decided against it in the end. Vinnie, a married man from Canada with three children conceived using donor sperm, rejected the offer of sperm from his father and brother because he didn't want to complicate the social relationships, 'they say money destroys friendships. Well I imagine children would destroy them even more'. Tammy, a married woman in California who is currently undergoing IVF with donor eggs, was all set to accept the offer of egg donation from one of her best friends until she realised the potential for conflict further down the line:

The therapist had asked the question if something happened to my husband and me what did she [egg donor friend] think should happen to the child...our response was that if something happened to both of us which is highly unlikely, our child would probably live with one of our sister and our family and she said don't you think it should be with its biological mother and I said technically l'd be the biological mother and that's when I realised there was the red flag. So we knew going into it that she would have more of a vested interest in our child.

In the same vein as Vinnie's response there is a definite sense that one of the major reasons Tammy didn't go down the route of using a friend as donor is that she didn't want to ruin that friendship. She stresses that 'she's a big important part of my life so I would expect her to be a big important part of my child's life. I wouldn't want to lose her as a friend because we shared something intimate, her genetic material'. These are the experiences of people who were faced with the very real possibility of using a known donor and had to make a decision about whether to accept that or not. For other participants the issue was whether or not to approach a friend about being the donor/surrogate. 
Based on the analysis of question 1,170 the majority of the participants in each of the three groups do not consider themselves likely to involve a friend as the donor. ${ }^{171}$ Conversely, the majority of participants in each jurisdiction do consider themselves likely to use an anonymous donor. Whilst the majority of participants in E\&W are most likely to use anonymous donors, the data also reveals a split in opinion in relation to using known donors. It is interesting that roughly half of the participants in each jurisdiction believe it is at least possible that they would consider a friend as a donor even though three quarters maintain that it's possible or likely they would use an anonymous donor. This seems to indicate that whilst many of these participants are open to the possibility of involving a friend as the donor, there is a clear preference for donors where there is no personal connection.

Figure 4: Type of Donor

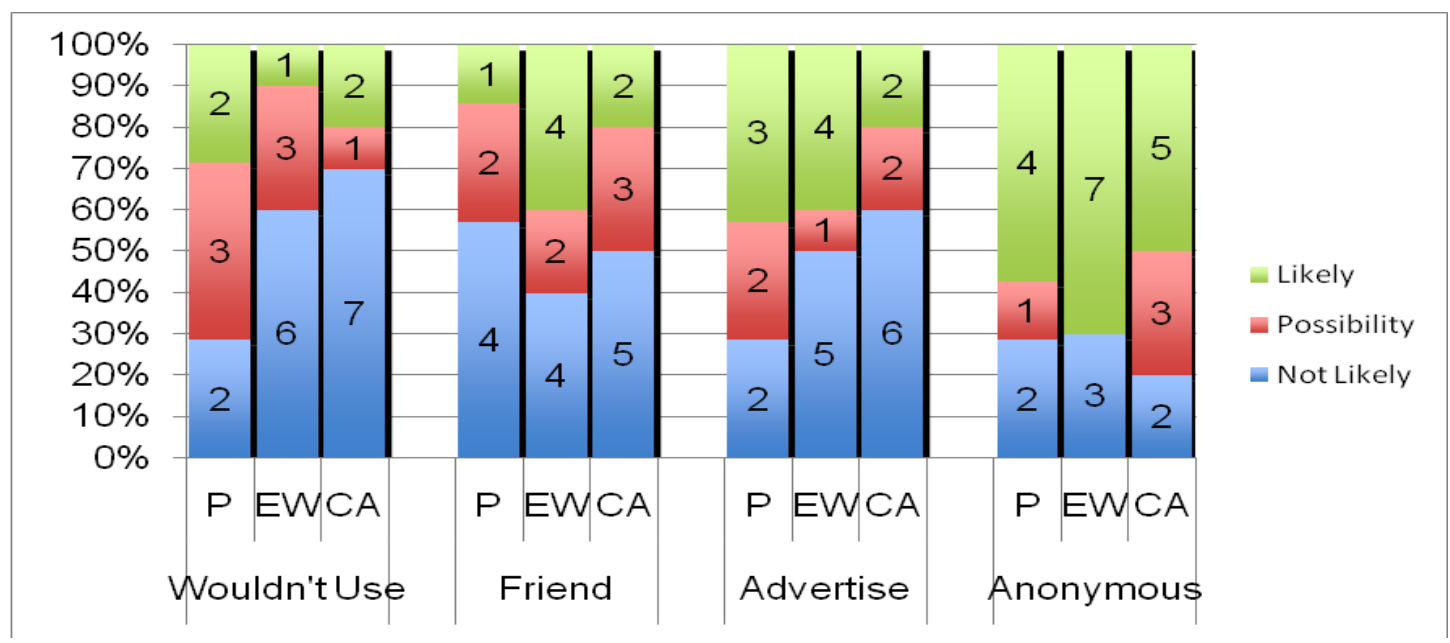

Figure 5: Type of Surrogate

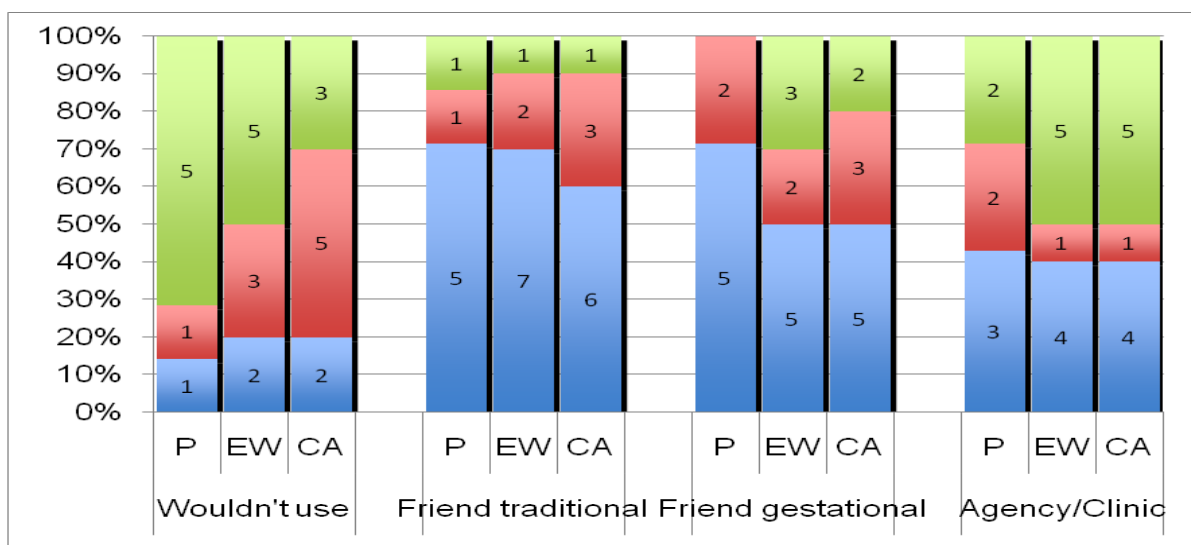

$\mathrm{P}=$ Pilot Group; EW = England and Wales group; $\mathrm{CA}=$ California group

\footnotetext{
170 See appendix 1 for the question.

171 see figure 4 below.
} 
A number of reasons for this reluctance to use friends as known donors and engage in co-parenting projects with them emerged during the interviews. One theme that was reflected in a number of participants' responses was that their position and role as a parent would be threatened by the heavy involvement of the donor in the child's life. As Carmen (CA) commented, 'I'd feel so threatened as a mother that this child will one day look at me and say that you're not even the mom and how hurtful that will be because I am the mom in every single way'. Therefore, in a situation involving egg donation, the mother would feel threatened by donor involvement because it may diminish the significance of her role in the child's life. This would also seem to be a concern for fathers in relation to sperm donors. As Eric (E\&W) highlights, 'I can't help feeling that if there was another father then that would make me less of a father and make my role in that child's life slightly less significant.' Some participants did not feel quite the same level of threat from donor involvement but rather the presence of a constant reminder that the child was not biologically theirs. As Connie (E\&W) remarked:

I think there are certain things that you can compartmentalise and almost shut away in your brain if there's not someone else who you would perhaps consider a father to your child around when it's someone you don't know a lot about.

These ideas of donor involvement constituting a threat and constant reminder focus very much on the effect donor involvement would have on the intended parents. Participants were also conscious of the detrimental effect donor involvement might have on the child. It's possible that this is felt more strongly amongst heterosexual couples where there may be an element of competition in parenting roles. ${ }^{172}$

There was a sense that the parents' feeling that their roles were diminished by donor involvement might have the undesirable effect of confusing the child and leading to a degree of competition for the child's affections. Eric makes the point that 'if it was my really good friend, I can see us almost being in competition and vying for that child'. This is supported by Connie's suggestion that 'with a known donor there could be a lot of emotional complications and blurred lines'. Sonia, a married woman from California who is currently undergoing treatment with an

172 As Eric commented in the context of same-sex relationships, 'l'd be inclined to think that the father would play a slightly different role to the mothers so there would be less competition.' 
anonymous egg donor, puts the case more strongly, stating that it complicates child raising goals, confuses a child and could possibly create authority issues, especially when the donor does not share the same views as my husband and I do'. This study, limited as it was by time constraints, has focused primarily on the views of parents. However, future research might meaningfully be conducted into the views of children conceived using ART, which seem to be underrepresented in much of the research. ${ }^{173}$

Based on the responses to the questionnaire it seems, therefore, that the majority of these participants, most of whom are married females, would prefer to use an anonymous donor and certainly do not want to engage in any sort of co-parenting project or have the donor heavily involved in their children's lives. Judging by the interview data it seems that there are various reasons for this which appear to belong to three broad categories: the desire not to ruin existing social relationships; the negative feelings donor involvement would engender for the parents; and the detrimental effect such an arrangement might have on the child. Whilst these results cannot be treated as representative of heterosexual couples, there is a definite suggestion from a number of participants that coparenting arrangements do not seem a very realistic possibility for such couples. ${ }^{174}$ This is an interesting finding in itself and raises the question of whether such arrangements might be more desirable and feasible for same-sex couples.

This research study could not form any concrete conclusions on the desirability and feasibility of co-parenting arrangements for same-sex couples. In order to do this a larger sample of same-sex couples would be required, preferably including couples that were currently engaging in co-parenting projects. However, some of the findings of this study do indicate that this would be a

\footnotetext{
173 See for example Leanne Smith. 'Is Three a Crowd: Lesbian Mothers' Perspectives on Parental Status in Law' (2006) 18(2) Child and Family Law Quarterly 231, where interviews were conducted with Lesbian mothers in order to conclude that the law did not adequately recognise their rights and responsibilities. See also Deborah Dempsey, 'Conceiving and Negotiating Reproductive Relationships: Lesbians and Gay Men Forming Families with Children' (2010) 44 Sociology 1145, 1160 where the author states: 'One question left begging is the extent to which children of different ages experience and understand these reproductive relationships.'

174 Thinking in relation to ART families seems to be different from thinking in relation to adoption where maintaining links with the birth parents and wider families is encouraged. See Jonathan Herring, Family law (Longman law series, 5th edn Longman, Harlow 2011) 685 - 7. In addition, continued relationships with the birth parents appear to be more common for adopted children. See Department of Health, Adoption and Permanence Taskforce Second Report (DoH, London 2002) 15.
} 
profitable area of further research. Firstly, there was a suggestion from the participants in this study that such arrangements might be a more realistic possibility for same-sex couples. As Connie highlights,

The only way I can see where [co-parenting] would make a difference and people would perhaps feel that's a beneficial thing to do is where it's perhaps a same-sex couple and they wanted the child to have a father figure or role model.

Perhaps even more telling is the comment from Anne-Marie, a female from Canada in a civil-partnership with 2 children born using anonymous donor sperm with identity release. She suggests that 'I would have been open to donor involvement but my partner wasn't. Therefore as a couple we were against donor involvement'. This is the first suggestion that donor involvement would be desirable in the concrete setting of the participant's life rather than in response to a hypothetical scenario. However, it does highlight that the responses of same-sex couples are not necessarily likely to be as homogenous on this issue as perhaps the views of the present participants were. In any event, from the results of this study, it appears that further research might fruitfully be conducted into the views of same-sex couples in relation to donor involvement and every attempt should be made to ensure an appropriate gender balance between male and female same-sex couples is achieved.

\subsection{Surrogate Involvement}

Interestingly there appears to be a greater reluctance to involve friends as surrogates (both traditional and gestational) ${ }^{175}$ than there is in relation to donors. A chi-square test ${ }^{176}$ was conducted in relation to question $4^{177}$ and this confirmed that the difference was statistically significance. The $P$ value was below the usual threshold for social science research ${ }^{178}(P<0.05)$ in both cases, namely $P=0.007$ in relation to traditional surrogates and $P=0.02$ in relation to gestational surrogates. This suggests that the difference is more significant in relation to traditional surrogates than gestational surrogates. Interestingly there is no statistically significant difference between the views of each of the groups in relation to using friends as donors $(P=0.782)$, traditional surrogates $(0.953)$

\footnotetext{
175 Traditional surrogates use their own egg, whereas gestational surrogates use the intended mother's egg or a donor egg.

${ }^{176}$ See appendix 4 for the contingency tables resulting from this test.

177 See appendix 1.

178 Alan Bryman, Social research methods (3rd edn Oxford University Press, Oxford 2008) 335.
} 
and gestational surrogates $(P=0.615)$. Whilst the results of these tests are interesting and do indicate differences, statistically speaking they do not achieve valid significance because in all cases the number of count values below 5 exceeds the $20 \%$ maximum for this test. ${ }^{179}$ This is largely due to the small sample size. Therefore, these results could be confirmed by further research in this area that was able to recruit a larger sample size. As a result, any conclusions drawn from the statistical analysis remain tentative although further exploration in the qualitative analysis of the interviews will provide additional insight into the reasons behind the responses to the questionnaire.

The data gathered from the interviews can help to explain why there might be a greater reluctance to involve a friend as a surrogate than as a donor. A number of participants indicated that using a friend as a surrogate would be more complicated than using a friend as a donor. Sonia highlights the concern that:

\begin{abstract}
'surrogates have a more emotional connection with the child since they gave birth to him/her. Known surrogates could potentially be even worse if they are overcome with emotional connection to the child and know who we are, where we live and has access to the child'.
\end{abstract}

The suggestion here is that the reluctance to use a friend as a surrogate is affected by the sense that there is a greater connection between surrogate and child than there is between donor and child. This is reflected in Connie's statement that 'with traditional surrogacy, it feels different because that person is the genetic and birth mother of the child. It feels more like adoption to me and I guess legally it is. I think that's why I would have different feelings about it'.

In addition to the greater emotional connection, and perhaps in a way related to it, another factor that influences the reluctance to use friends as surrogates is the reluctance to use surrogacy in general. Based on the results of the questionnaire, a greater number of participants indicated that it was at least possible if not likely that they would not consider surrogacy than those who indicated the same in relation to sperm donation. ${ }^{180}$ This is perhaps because the vast majority of participants had undergone treatment using donor sperm, whereas only a very small minority had used a surrogate. Therefore, it may well be the case that the results would differ if the sample included more people who

\footnotetext{
179 Ibid 335.

180 See figure 5 above.
} 
had used surrogacy. This seems to be borne out by the greater number of individuals in the pilot group, for whom this was a hypothetical scenario, who consider it at least possible, if not likely, that they would not use sperm donation compared to the groups who had actually undergone the treatment. ${ }^{181}$

Nevertheless, there is a sense amongst some of the current participants that surrogacy presents additional complications which makes them less likely to consider this option and in turn would make them feel that using a friend as a surrogate would be an undesirable option. Dianne (E\&W) comments that 'surrogate involvement presents slightly different issues because it's a woman, especially if they are genetically related and they carried the child. I don't think I'd ever use that method or even consider it'. For Eric, the difficulty seems to be more of a moral one that is created by the presence of the surrogate:

It's not really right what we're doing because that child should be with his or her mother and we shouldn't really cut that mother out. If it's an anonymous person who doesn't want anything to do with the child then I'm not in that position and it's not an issue.

Perhaps this adds to the sense that surrogacy is seen as somehow not well accepted in society, which may have an impact on participants views. As Kathy, a married woman from E\&W who has a child using a traditional surrogate, comments, I have pics etc. to show Molly when she is older and of course we will not keep anything from her, I am hoping that surrogacy might be more acceptable by then!'

Despite this, the view that known surrogate involvement presents unique issues compared to known donor involvement is not universally accepted. Based on the results from the questionnaire it can be seen that the views of participants in California do not differ in relation to known surrogate involvement as compared to known donor involvement. ${ }^{182}$ In response to the question whether surrogate involvement presents similar or different issues as donor involvement, ${ }^{183}$ Annabel's (CA) answer was 'just the same. Absolutely the same. I don't think that just because you were pregnant and with the child for 9 months that makes you any more involved than a sperm donor.'

181 See figure 4 above.

182 See figures 1 and 2 above

183 Question 3 a. See interview guide in appendix 2. 
It is interesting to note that the results from the questionnaire indicate that in general participants from E\&W see some surrogate involvement as more desirable than some donor involvement, whereas participants from California feel the same about both. ${ }^{184}$ One possible explanation for this is the different legal and social context of these two jurisdictions. In California, surrogacy is perhaps seen as more acceptable with commercial surrogacy being permitted. In E\&W, however, commercial surrogacy is not allowed and HFEA regulated clinics are not permitted to assist in finding a surrogate. In addition to this, the law in California recognises the intention of the intended couple to a greater extent. This has resulted in the intended couple being considered the parents of the child rather than the surrogate. As discussed in chapter two, however, in $\mathrm{E} \& \mathrm{~W}$, this is not possible without a court order. Perhaps then participants in California feel just as comfortable excluding the donor as they do the surrogate because that is culturally and legally accepted there whereas here surrogacy laws have not necessarily developed in that way. This is something that will be considered in more depth in the following chapter.

\subsection{Conclusion}

Overall, therefore, this group of participants were quite resistant to the idea of co-parenting in relation to their own families. However, many of the participants indicated that it may well be a realistic possibility for other families, particularly those who are willing to use a known donor. Further research is therefore required, in relation to same-sex couples in particular, but also in respect of single parents by choice because their decisions to involve or exclude the donor could be instructive and provide a useful point of comparison. Surrogate involvement seems to present different issues, for participants in E\&W at least, than donor involvement does. Therefore, further research into the views of those who have made use of surrogacy would provide greater insight into this. There does not appear to be such difference in opinion among Californian participants and one potential explanation for this may be the different cultural and legal recognition of surrogacy in these two jurisdictions. This chapter has focussed on participants' views in relation to donor and surrogate involvement in the child's life. The following chapter will now consider how this should be reflected in the law of parenthood.

${ }^{184}$ See figures 1 and 2 above. 


\section{Legal Recognition}

\subsection{Introduction}

The previous chapter explored the first two research questions, namely the desired level of donor/surrogate involvement and the reasons for this. This chapter will focus on the final research question, namely how the law should regulate donor/surrogate involvement through the law of parenthood. In order to do this, the questionnaire presented the legal consequences of using a known donor and surrogate through the use of vignettes. ${ }^{185}$ The results of these questions are displayed graphically below. ${ }^{186}$

Figure 6: Legal Recognition of Known Donor

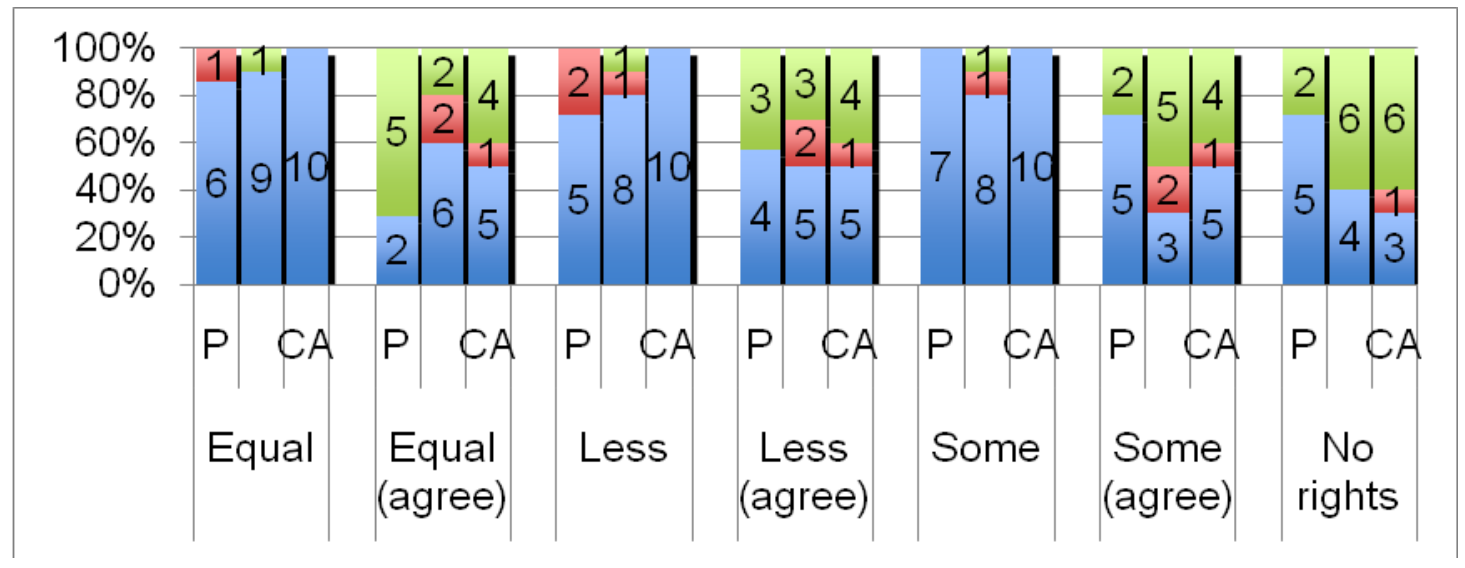

Figure 7: Legal Recognition of Traditional Surrogate

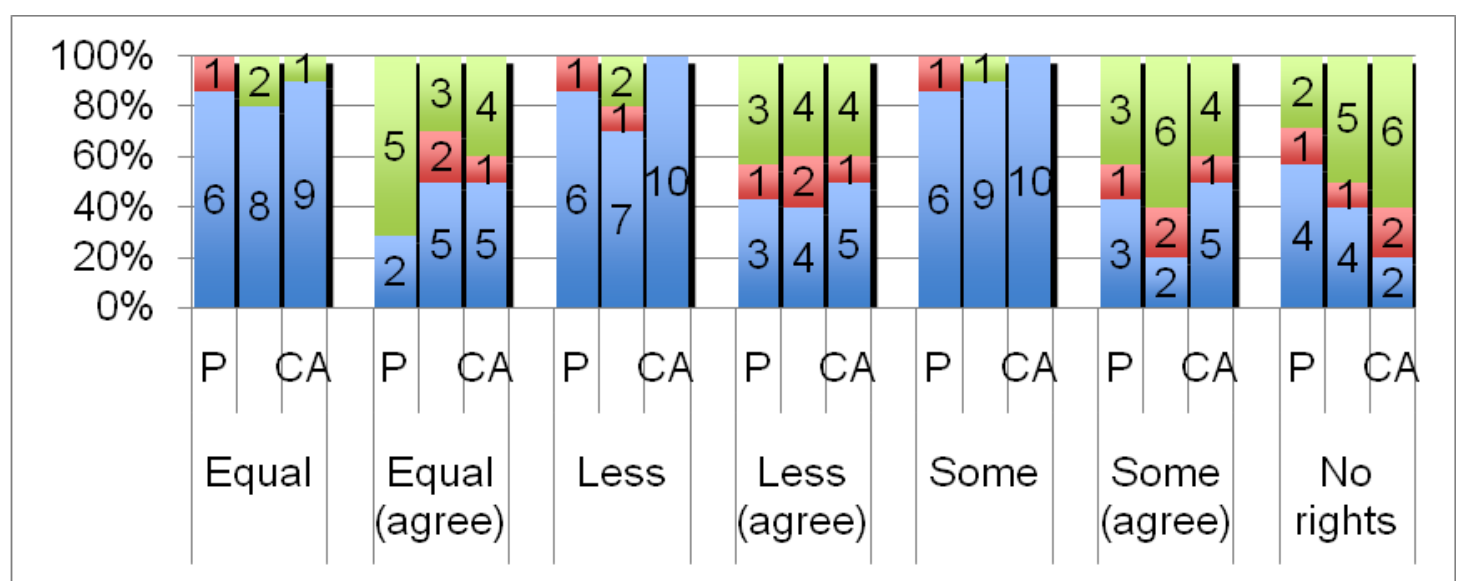

185 See questions 2 and 5 in appendix 1 .

186 See figures $6-8$. 


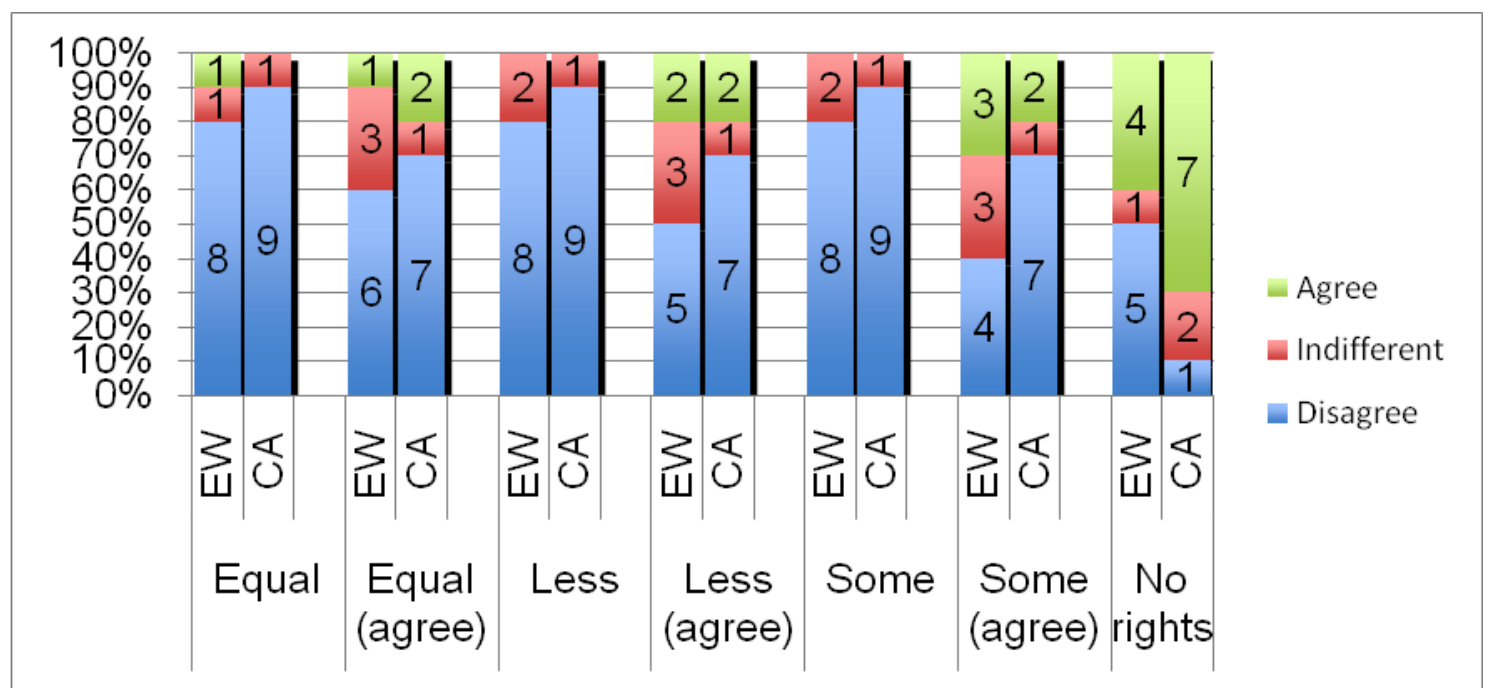

$\mathrm{P}=$ Pilot Group EW = England and Wales group $\mathrm{CA}=$ California group

\subsection{Known Donor}

Based on the results of the questionnaire, it would seem that the vast majority of participants in each group are against granting a known donor default rights in the absence of agreement from all parties. ${ }^{187}$ There is unanimity on this point amongst Californian participants and the vast majority of the pilot group and participants from E\&W seem to feel the same way. Interestingly, this does not lead to such a strong majority in either jurisdiction feeling that the donor should have no rights whatsoever in relation to the child. In fact, the majority of the pilot group disagree that the donor should have no rights in relation to the child. One might hypothesise from the results of the questionnaire that the discrepancy between the pilot group and other jurisdictions could be as a result of the former approaching it from a more hypothetical and perhaps idealised point of view without having fully thought through the implications of their views. One might also suggest that the reason there is not such a strong majority in favour of giving the donor no rights as there was in relation to not considering him an equal parent is because some middle ground is envisaged. One of the limitations of survey research, however, is that it provides no basis for confirming any of this speculation. In order to explore the motivations behind these interesting differences the interview data need to be examined.

187 See figure 6. 
One of themes that emerged quite strongly in a number of participants' responses was the idea that the child should be able to dictate the terms of the relationship when he or she is old enough to be able to make that decision. As Carmen (CA) commented:

If the child would like the opportunity to meet their donor after they were 18 and the donor was willing to meet the child, I would not feel that I have control over that. I would make the information available if the child wanted to meet the donor

This notion of transparency in order to facilitate any relationship the child might want with the donor in the future is reflected in the answers of a number of participants. Connie (E\&W), for example, stresses that:

I do feel strongly that children who are donor conceived should have the right to know how they were conceived... If they wanted to I wouldn't discourage them from looking into the donor and it's up to the child what form that relationship takes.

There was no suggestion that there would be any secrecy surrounding how the child was conceived. Participants felt quite strongly about that, which is illustrated by Tammy's suggestion that she is 'all for transparency and honesty'. Perhaps, therefore, the need to be open with the child and preserve the possibility of a relationship with the donor in the future, if the child desires it, influences these participants' views in relation to the rights a known donor should have. This issue seems to have been more prominent in relation to surrogacy and will, therefore, be discussed more fully in the following section.

The desire for transparency and the possibility of a future relationship may partially explain the reduction in the majority of those in favour of granting no rights whatsoever to the known donor compared with the larger majority in favour of no defaults rights for the donor. These opinions may be felt more strongly in the pilot group or at least are not tempered by having had to actually face and address these issues. These issues are, however, also somewhat theoretical even for the participants in the two jurisdictions because none of them are actually in a situation involving a known donor. Despite this, there is a suggestion from some participants that if they were faced with this situation they would not wish the donor to have any default legal rights as a parent but at the same time they would not wish to cut them out completely. The desire to seek some kind of middle ground is evident in the comments made by Julie, a 
married woman from E\&W with two children conceived using an anonymous egg donor, in response to a hypothetical situation involving a known donor:

I would also want to tell the child at a very early age, so that it seemed natural. We would have to find a way of balancing a complex situation, allowing [our friend] information and possibly a relationship, maybe as if an Uncle.

An additional explanation for not wanting to cut a known donor out legally could be that it would not be in the child's best interests. Susan, a female from E\&W in a same-sex relationship, explains her reluctance to deny a known donor any legal rights in the following terms:

I think it is extremely important for a child to know who they are and where they are from and whilst having a father figure may cause some difficulty between myself and my partner I still believe this would be in the child's best interest.

This concern may be particularly relevant for same sex couples. ${ }^{188}$ However, further research would have to be undertaken in order to confirm this.

There seems to be a number of explanations for the significant proportion of participants that are reluctant to legally cut the donor out completely - the desire for transparency, the urge to protect future relations, the hope of finding some middle ground and the belief that it may not be in the best interest of the child. Despite this, there appears to be a general consensus amongst all the groups that a known donor should not be afforded the legal recognition of a parent when there is a lack of agreement between all parties. One theme that has emerged quite strongly in the data is the idea of overcomplicating an already complicated situation. As Tammy highlights

Raising a child with my husband who l've known for 10 years is challenging enough...if I had a third person involved in the process I just think that would be really confusing and complicated especially if it was someone they knew.

As a result of this, there is a suggestion that legal recognition of the donor could cause too many problems in raising the child. As Kathy comments:

I definitely would not like any legal relationship, too many parents!...I really feel there could be problems that arise later on

\footnotetext{
188 As Eric notes, 'in the case of a female lesbian couple, I would be more inclined to say the
} father should have more rights because he is the child's only father'. 
regarding the child's upbringing etc. as the saying goes too many cooks spoil the broth!

Therefore, this sense that granting a known donor equal parental rights or even any significant rights might complicate the raising of the child is a major factor in these participants' reluctance to afford a known donor legal recognition.

A number of participants elaborated on the different ways that the complications of involving three people in the raising of a child could manifest themselves. One suggestion is that the child could play parents off against each other, and although this can occur in two-parent families, it may be exacerbated when three people are involved. As Dianne commented,

I think if you give the sperm donor some sort of rights or involvement in the upbringing of the child it could cause problems for the child. I can imagine that if the child didn't get what he or she wanted from his social parents that he might go to his biological father and try to use the situation.

This in turn could lead to confusion in the child's mind as to which adult performs which role in his or her life which could have a detrimental effect on the environment in which the child is being raised. This is a factor that fed into Vinnie's decision not to use a known donor. As he notes, 'one of the reasons we decided against a friend/family donor was to avoid complicating the parenting roles'. This notion of confusing the child resonates in the answer of a number of participants. Kathy, for example, stresses that 'The surrogate/donor being legally recognised could lead the child into confusion "who is Mummy" or "who is Daddy"'.

The potential complication and confusion in relation to raising the child and performing parental roles certainly appear to have influenced many of the participants' views against recognising the donor in any legal way. It would seem that participants' views against legal recognition correspond to their lack of desire to have the donor involved in the child's life, which was discussed in the previous chapter. In order to confirm this, a Spearman's Rank Correlation test was conducted which confirmed that there is a strong negative correlation between the likelihood of heavily involving the donor in the child's life and the 
level of agreement that the donor should have no legal rights. ${ }^{189}$ This would suggest that the more likely participants are to consider involving the donor in the child's life, the less likely they are to believe that the donor should have no legal rights. This conclusion, however, must remain tentative given the small sample size. Further research, particularly involving participants who are likely to approve of donor involvement, would be required to confirm this.

The majority of these participants would be unlikely to consider allowing a known donor to be involved in the child's life to any great extent and consequently feel that the donor should not have any legal rights. Despite this, there is a definite sense that, if the intended parents and donor want to reach an agreement on the level of involvement and legal recognition of the donor, this should be allowed to happen. According to figure 6 , views are fairly evenly split as to whether the donor should or should not be afforded legal recognition if everyone is agreeable. One explanation for this is the absence of what Ronald Dworkin termed hostile external preferences, namely a preference restricting the assignment of goods or opportunities to others. This can be contrasted with personal preferences, which is a preference in relation to one's own enjoyment of certain goods or opportunities. ${ }^{190}$ There seems to be a broad consensus amongst these participants that, as a matter of personal preference, coparenting/heavy donor involvement is not for them, but as a matter of external preference, people should be free to decide the level of donor involvement and the legal recognition that attaches to that. This is summed up by Connie's comment, reflected in the answers of a number of participants, that 'if parties involved wanted it to be that way, who am I to say that's the wrong thing to do?' Some, such a Dianne, conclude from this that the law, therefore, should not impose a restriction to two parents on those families who desire more:

I don't think that's the laws place...I think there are scenarios where that wouldn't work long term but I think there are certainly circumstances where I think it can work very well and the child is loved by three people instead of two which can't be a bad thing...

\footnotetext{
189 The correlation coefficient was -0.6 , which is considered to indicate a strong negative correlation because it falls between -1 and -0.5 . In addition this test would be statistically significant because the significance level is $p=0.01$, which is below the accepted level of 0.05 . 190 Ronald Dworkin, Taking rights seriously (Duckworth, London 1977) 234.
} 
Carmen would seem to agree that donors should be afforded legal rights if all parties agree but remains firm on the point that this should not lead to default recognition of their rights:

I do think that the law should recognise if all parties are in agreement that there is some kind of co-parenting relationship but I don't think it should be something that is just a flat out law because I think that just makes it messy for couples who want a known donor but don't want any co-parenting done.

This view is fairly representative of the opinion of the majority of the participants in relation to known donors. There is also a degree of parity between the views of participants from E\&W and those from California. The legal recognition of known surrogates, however, seems to cause a greater divergence of opinion, which will now be explored in some depth.

\subsection{Known Surrogate}

Based on the results of the survey, participants in both California and E\&W have broadly similar opinions in relation to default rights for donors, traditional surrogates and gestational surrogates, namely that they are largely against them having any default rights. ${ }^{191}$ In addition, there is a very similar split in opinion in relation to granting the donor rights if everyone is agreeable regarding traditional surrogates, as was observed above in relation to donors. Therefore, participants in E\&W are generally less resistant to the surrogate having some rights if everyone is agreeable than participants in California, as was the case with donors. As was discussed above in relation to donors, participants' views that a known surrogate should be able to have a recognized relationship with the child seems to be motivated partly by a desire to facilitate the child's ability to have a future relationship with their birth mother if they choose. ${ }^{192}$

However, the issue on which there is the most divergence in opinion within each group of participants, when compared to views in relation to donors and traditional surrogates, is the legal recognition afforded to gestational surrogates when everyone is agreeable. Both groups of participants are more reluctant to allow a gestational surrogate any significant legal rights, whereas opinion in

\footnotetext{
191 See figures $6-8$.

192 As Connie comments: 'you wouldn't want the child to go suddenly when they are in their teens, that lady across the road who we see every day is my genetic mother and my birth mother. It would have to be done so it's not a shock to the child'.
} 
relation to donors and traditional surrogates was divided. The most interesting difference, however, is that the majority of participants in the California group are reluctant to grant a gestational surrogate any legal rights even where there is agreement. This stands in contrast to the E\&W group where opinion is much more divided on the issue. ${ }^{193}$

There could be a number of explanations for this divergence of opinion between Californian participants and those from E\&W. As Vinnie commented, answers to these questions depend to an extent on one's 'religious, social worldview'. Perhaps surrogacy is more culturally accepted in California and as a result more on a par with gamete donation than is the case in E\&W. This could partially explain why Californian participants are just as comfortable excluding the surrogate as they, and we, might be in relation to the donor. In this regard, the cultural and social context in which the law operates is important in understanding differences in responses between the two jurisdictions. However, it is also important to recognize that the law regulates the issue of gestational surrogacy in very different ways in the two jurisdictions.

As alluded to in the previous chapter and discussed in depth in chapter 2, Californian law, at least in relation to gestational surrogates, gives greater weight to the intention of the parties than it does to the fact of gestation. By contrast, the law of E\&W considers the birth mother to be the legal mother until she relinquishes that status. This difference in legal recognition was aptly summed up by Carmen's (CA) comment that:

The laws are different in the US so the ways l've always looked at it may be a little different. In the United States it's all about intent. If the intent of the donor/surrogate is not to parent the child but just to be the donor/surrogate then they are not considered the parents at all. Their name is not on the birth certificate. It is the intent that counts in law.

This notion that it is the intentions of the parties that should be recognised by the law is reflected in the opinions of a number of participants. Annabel (CA) stresses that, 'if you are agreeing to do that for somebody else then you should be prepared for the fact that you are doing this for a couple so they can have their own child or you shouldn't do it'. Therefore, there seems to be a general sense amongst the Californian participants that gestational surrogates go into

${ }^{193}$ See figure 8. 
the surrogacy arrangement with their eyes open and that they need to follow through on the commitment they made.

Opinion on this issue is, however, more divided amongst the participants from $\mathrm{E} \& \mathrm{~W}$. There is a sense amongst some that intentions need to be honoured in a sperm donor arrangement but that surrogacy presents slightly different issues. Connie (E\&W) highlights that 'to me a donor is just a donor not a parent to that child nor should they be expected to be because that's not what anyone bought into when they agreed'. However she goes on to stress that 'I think the surrogate should initially be considered as the legal mother. It has to be the person to give birth to the child because that's the only thing you can track'. Therefore, there is a suggestion here that there is something inherently desirable about recognising the birth mother as the legal mother, despite the fact she had originally agreed to a surrogacy arrangement in which she would not be the legal mother.

This, however, does not reflect the opinion of a number of participants from $E \& W$ who feels that the act of gestation affords the surrogate no greater claim to parenthood than say a donor. As Dianne (E\&W) comments, 'I almost see the carrier as just an oven for 9 months. I don't think they have any right to the child at all'. This is supported by Eric's (E\&W) suggestion that 'I don't see a gestational surrogate as having any connection to the child. I just see her as a human test-tube basically'. Therefore, whilst some view the act of carrying the child as a sufficient trigger for legal parenthood, others feel that the lack of biological connection means that such legal recognition is not deserved. As Kathy (E\&W) comments:

The law is weird at present regarding host surrogacy, even though the surrogate has no biological link to the baby she usually has to have the last say on any medical procedures the baby may need until the parental order is in place be it donor or an embryo from the Intended Parents.

This raises the question of how important biology should be in recognising legal parenthood following ART. There is a sense amongst participants both from California and E\&W that biology should not necessarily be determinative of legal parenthood but rather caring for the child and the intention to care for the child should have greater influence. As Tammy (CA) notes, '[surrogates] have no 
legal rights or obligations... genes don't create the bond, parenting creates the bond.' This is reflected in the views of a number of participants. Dianne, for example, stresses that:

if I'm in a relationship and decide to have a child with the partner and we can't carry the child, we are still the child's parents and it's the upbringing that we provide that child that makes us its parents. The child is only there because we decided to create it.

There is a suggestion that the intentions of the intended parents to have the child should be determinative of legal parenthood because 'but for' these intentions the child would not exist. Interestingly this view was held by a number of participants in each jurisdiction including the pilot group.

\subsection{Co-Parenting}

In the final section of this chapter, the implications of the foregoing sections for the legal recognition of co-parenting arrangements will be discussed within a socio-legal theoretical framework. Socio-legal theory suggests that the values inherent in the research should be brought to the forefront. ${ }^{194}$ In the context of family law research such as this, the implicit aim is to 'create a more socially just society'. ${ }^{195}$ In relation to the present study this pertains to the social exclusion of alternative families by not legally recognizing the family structures they create, which are a legitimate expression of what Foucault terms the 'practices of freedom. ${ }^{196}$ The critical stance that has permeated this study is that the present curtailment of this freedom lacks the necessary justification, but is rather underpinned by an uncritical acceptance of the traditional two-parent model. ${ }^{197}$

This seems to be reflected in the empirical data collected, which suggests that participants had no principled objection to recognising co-parenting arrangements and did in fact see some benefit to that. This would seem to fit with the idea that it is important that the law of parenthood honours parties' intentions, as discussed in the previous section. In light of this, participants'

\footnotetext{
194 See Simon Jolly, 'Family Law' in Philip Thomas (ed) Socio-Legal Studies (Dartmouth, Aldershot 1997) 350.

195 M.D.A Freeman, 'Towards a Critical Theory of Family Law' (1985) 38 Current Legal Problems 153, 155.

196 Michel Foucault, The History of Sexuality. Volume 1: An Introduction (Penguin, Harmondsworth 1979). See also Jeffrey Weeks, Invented Moralities: Sexual Values in an Age of Uncertainty (Polity Press, Cambridge 1995) 50 - 58.

197 See Julie McCandless and Sally Sheldon. 'The Human Fertilisation and Embryology Act (2008) and the Tenacity of the Sexual Family' (2010) 73(2) MLR 175, 192.
} 
ambivalence to legally recognising co-parenting arrangements may be explained by a lack of personal experience with them and an inability to see how the very real concerns associated with any type of shared parenting are going to be overcome. ${ }^{198}$

There is a sense that people will and do create these types of arrangements regardless of the legal recognition. As Tammy highlights 'people do it anyway and they just have their own mutual agreements'. However this does not justify the lack of legal recognition, which can lead to social exclusion. Carmen stresses the fact that legal recognition and social recognition go 'hand in hand' and that not recognising co-parenting arrangements in law means that there 'is some denial' of social recognition for these alternative family forms. The law's lack of recognition for these families would seem to be unjustified and untenable given the potential for social exclusion this could create which runs contrary to the drive towards equality amongst family forms that exist within society.

\subsection{Conclusion}

The previous chapter concluded that co-parenting arrangements were not something that the majority of these participants sought. However, there was a sense of recognition that they might be desirable for some people, particularly same-sex couples. The previous sections have noted that views are broadly divided on legally recognising the donor/surrogate if everyone is agreeable. However, there is a greater resistance do doing so if the surrogate is a gestational carrier and not genetically related to the child. This implies that legally recognising biology is important for these participants. However, when the issue is explored further biology is revealed as important but not as important as the intention to parent the child.

When the importance of intention is considered in the context of co-parenting arrangements, the question the law must answer is whether it will reflect the intentions and realities of families engaged in these arrangements or whether there is some compelling reason to adhere to the two parent model. ${ }^{199}$ No

\footnotetext{
${ }^{198}$ As Kathy comments 'we are all different, so what is right for us may not be for other couples and if an arrangement is made that parties are happy with...then good luck to them but I really feel there could be problems that arise later on regarding the child's upbringing etc.'

199 The intentionality argument raises the issue of whether the law in England and Wales should take the same route as the Canadian law in allowing three parents to be legally recognised. For more on this see Chapter 2: Literature review $\mathrm{p} 23$.
} 
definitive recommendation can be made on the basis of the present study. However there is a definite sense that the current participants would not be opposed to recognising such arrangements in principle but further research will be required to assess how appropriate such legal recognition would be. The present study has been focussed on the views of parents and potential parents. Responses from participants indicate how this tends to ignore child welfare issues. Potentially, therefore, it will be important in future research that the views of donor conceived children are adequately represented. ${ }^{200}$

200 Arguments in relation to child welfare may well take the debate in a different direction from those focussing on equality between parents. The best interests of the child need not, however, be an absolute trump over all other arguments. See on this Helen Reece, 'The Paramountcy Principle' (1996) 49 Current Legal Problems 267. 


\section{Conclusion}

Through the use of socio-legal research methods, this project has sought to test the law's implicit assumption, in the context of assisted reproduction, that a person can have no more than two parents. Despite limitations on the size of the sample, the study has canvassed a range of views on the involvement of donors and surrogates and the legal recognition they deserve. The impression that has emerged from analysing the data, using a grounded theory approach, is that co-parenting arrangements may not hold the same appeal for heterosexual couples as they potentially do for same-sex couples. Although there didn't seem to be a strong objection in principle to co-parenting arrangements, there was a definite suggestion amongst the mainly heterosexual participants in this study that it was 'not for us'. Conversely, co-parenting arrangements were seen as being of potential benefit to same-sex couples, provided everyone was agreeable. During the course of the research, it became clear that the views of more same-sex participants would be beneficial given the emerging suggestion that these arrangements would be of more interest to this group. ${ }^{201}$ This is, however, a hard-to-access group and further research in this area would benefit from a longer period in which to recruit the sample.

The project successfully combined quantitative and qualitative methodology in a mixed method approach to the topic. The quantitative data analysis indicated that participants from both England and Wales and California shared the same reticence in relation to donor involvement and legal recognition of donors but that there was a greater reluctance on the part of participants from England and Wales to cut the surrogate out completely. The qualitative data analysis revealed that in England Wales this reluctance to sever the link with the surrogate is motivated by a sense that there is a strong connection between the surrogate and the child. By contrast, there was a sense among the Californian participants that surrogates were in a similar position as donors and must honour their intentions. This difference in opinion may be partially explained by the different social and cultural context that operates in these two jurisdictions. This corresponds with the argument put forward in the literature that in the

201 For a discussion of the sampling strategies used in response to this see Chapter 3: Methodology pp $31-32$. 
context of ART intentionality is a stronger basis for conferring legal parenthood in the context of ART than biology. ${ }^{202}$

Overall, therefore, this project has been a successful initial exploration of the issues surrounding co-parenting. It has been a learning experience in terms of the sampling techniques required to recruit participants in these hard to access groups but also in terms of the most beneficial scope of future research. This project has been focussed on the views of donor parents. However, as has been pointed out by a number of participants, future research might fruitfully consider the views of children born using ART. It would be particularly useful to recruit participants currently engaging in some form of co-parenting, perhaps from a jurisdiction where that family form can be legally recognised such as Canada. This study has successfully canvassed a range of views on coparenting following ART and attempted to triangulate this with the existing literature in order to gain a fuller understanding of the issues. It has, however, also indicated areas, which might benefit from further research.

${ }^{202}$ For a detailed discussion of this see Chapter 2: Literature Review 17 - 22. 


\section{Appendix 1: Information Sheet, Consent Form and \\ Questionnaire $^{203}$}

\section{Project Information for Participants}

The researchers and the project

This research is being conducted by Philip Bremner (pdb203@exeter.ac.uk), a postgraduate student in the School of Law at the University of Exeter, as part of his Masters degree dissertation project. The project is being supervised by Anne Barlow (A.E.Barlow@exeter.ac.uk), who is Professor of Family Law and Policy. The aim is to seek parents' views about the involvement of donors and surrogates in the lives of their children who have been born using assisted reproductive technology (ART). The hope is to use the data from this research project to evaluate how suitable the law is in different jurisdictions, particularly in regard to who is considered a parent of children born using ART.

How were the participants selected?

The participants in this project are (potential) parents of children who were born using ART, which includes sperm donation, egg donation and surrogacy. This study was advertised through various support groups and agencies in order to recruit participants, where a link was posted to this online survey.

What will participants be asked to do?

If you decide to participate in this project, please read the consent form below and indicate that you agree to this by ticking the box. Once you have done this you will be able to continue on to the questionnaire which should not take more than 20 minutes to complete. At the end of the questionnaire you will be asked for your contact details if you wish to be involved in further research. You may then be asked to participate in a follow-up interview, which will explore the answers you gave to the questionnaire in more detail. We only require a selection of participants to take part in interviews.

Arrangements for Withdrawal of Participants

Your participation in the project is entirely voluntary and you are entitled to withdraw from the project at any point, and are not required to give your reasons for so doing. Please be assured that you are completely free to decline to answer any question if you are not comfortable doing so.

\section{Arrangements to Ensure Confidentiality}

The interviews will be transcribed and the information contained in the transcripts, along with the questionnaires, is kept anonymous so that your true identity and answers will not be attributed to you personally in any publication. The transcripts and questionnaires will be saved on a PC that will be password protected and stored in a locked room.

203 These all appeared together as part of the online questionnaire. As the questionnaire was downloaded from the website, further formatting was not possible. 
Results will be written up in the form of a Masters degree dissertation, parts of which may be published as articles within respected academic journals and presented in the form of conference papers. In all cases professional research ethics will be adhered to and appropriate confidentiality maintained; we will seek to provide a balanced and scholarly depiction of research findings.

Arrangements for Provision of Results to Participants

If you would like a summary of the outcome of the project please e-mail Philip and he will be happy to send this to you once the project is concluded.

\section{Consent Form *}

1. I have read and understand the above Information Sheet relating to the Social Parentage and Assisted Reproduction project. 2. I understand the purposes of the project and what will be required of me, and any questions I have had have been answered to my satisfaction. I agree to the arrangements described in the Information Sheet in so far as they relate to my participation. 3. I understand that participation is entirely voluntary and that I have the right to withdraw from the project at any time. 4 . I have received a copy of this Consent Form and of the accompanying Information Sheet. 5. I am happy for anonymised data from this research project to be retained for up to 5 years for use in subsequent $\mathrm{PhD}$ research.

By ticking this box you agree to the above statements

We may wish to contact you for participation in future PhD research. If you are happy for us to retain your contact details for up to 3 years please tick the box. You are not bound in any way to participate in future research and may withdraw consent to us retaining your contact details at any time. 


\section{Your details}

Please complete this short section about yourself

\section{Gender *}

Please select one of the following choices

Male

Female

\section{Age *}

Please select the appropriate age band

O $18-24$

$25-34$

O $33-49$

O50-64

O65+

\section{Where do you live? *}

East Midlands

\section{Occupation}

\section{Relationship Status *}

Please select one of the following choices

Currently married

Currently in a civil partnership

Living with different-sex partner but not married

Living with same-sex partner but not in a civil partnership

In a relationship with different-sex partner but not living together

In a relationship with same-sex partner but not living together

Not in a relationship 


\section{Partner's Details}

Please complete this section about your parther

Age *

Please select the appropriate age band

U) $18 \cdot 24$

$025 \cdot 34$

35.49

50.64

O65t

Dooupation

Page 4

After page 3 Continue to next page

\section{Sperm Donor Scenario}

Sam and Christina are in their early $30 s$ and wart to have a child but need donor sperm in order to do this. Under currert law if this is done through a private arangement outside a licensed fetility dinic thenthe sperm donor would be considered the faher of the child. However if this is done in a licensed dinic, Sam and Christine will both be the parents of the ctild. *

If you (and your partner) were in Sam and Christinas position how lke ly would you be to corsider doing each of the following?

$$
\text { Veny likety Quite lkety } \begin{gathered}
\text { It is a } \\
\text { possibility }
\end{gathered} \text { Not wenylkely Not at all }
$$

Wiould not consider using donor sperm at all (perhaps consider other options such as adoption)

$\begin{gathered}\text { Ask a close male friend to } \\ \text { donate sperm and organise } \\ \text { insemination at home }\end{gathered}$
$\begin{gathered}\text { Ask a close male friend to } \\ \text { donate sperm and go to a } \\ \text { licensed fertility dinic for } \\ \text { treatment }\end{gathered}$
$\begin{gathered}\text { Segk to make contactwith a } \\ \text { potential donor privately (e.g. } \\ \text { through a support group) and } \\ \text { organise insemination at } \\ \text { home }\end{gathered}$


Sedk to make contact with a potential donor priva ately (e.g. through a support group) and go to a licersed fertility clinic for treatment

Go to a licersed fertity clinic for treatment using

anonymous donorsperm

0000

(3)

0

0

Q
0
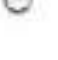

Please briely state your reasons for the above answer

(optional)

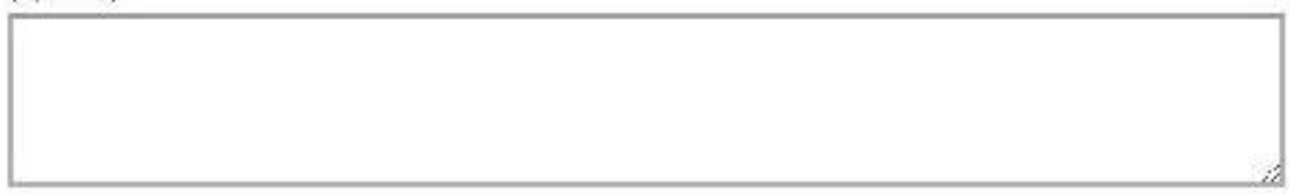

Sam and Christina have decided to acoept the offer of sperm from their friend Mi ke and go to a licensed clinic. Under the current law Sam and Christina woud be considered the child's legal parent(s) provided both partners consent to the trea ment, wheress $M$ ke would have no legal cornection to the child (Emily). M ke is willing to be involved as much or as little in Emily's life as Sam and Christina want*

Please in dicate how st onghy you agree with each of the following statements about the default position the Ian should take

\begin{tabular}{|c|c|c|c|c|c|}
\hline & $\begin{array}{c}\text { Strongly } \\
\text { agree }\end{array}$ & Agree & Indiffe rent & Disagree & $\begin{array}{l}\text { Stronghy } \\
\text { dis agree }\end{array}$ \\
\hline $\begin{array}{l}\text { mike should be corsidered } \\
\text { Emity's parent alongside } \\
\text { Sam and Christina, with } \\
\text { equal legal rights in relation } \\
\text { to Emily regardless of } \\
\text { whether Sam and Christina } \\
\text { agree to this }\end{array}$ & 0 & 0 & 0 & 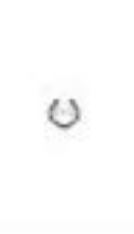 & $\mathrm{O}$ \\
\hline $\begin{array}{l}\text { Whike should be corsidered } \\
\text { Emity's parent alongside } \\
\text { Sam and Christina, with } \\
\text { equal legal rights in relation } \\
\text { to Emity if Sam and Christina } \\
\text { agree to this }\end{array}$ & 0 & 0 & 0 & & $\sigma$ \\
\hline $\begin{array}{l}\text { Mike should be corsidered } \\
\text { Emily's parent alongside } \\
\text { Sam and Christina, with } \\
\text { fewer legal right in relation } \\
\text { to Emily regardless of } \\
\text { whether Sam and Christina } \\
\text { agree to this }\end{array}$ & 0 & 0 & 0 & & $\rho$ \\
\hline $\begin{array}{r}\text { Mike should be corsidered } \\
\text { Emihys parent alongside } \\
\text { Sam and Christina, with } \\
\text { fewer legal rights in relation } \\
\text { to Emily if Sam and Christina } \\
\text { agree to this }\end{array}$ & $Q$ & 8 & 0 & 3 & $\mathrm{O}$ \\
\hline $\begin{array}{l}\text { Mike should not be } \\
\text { consider ed Emity's parent but } \\
\text { should still have some rights }\end{array}$ & & & & & \\
\hline
\end{tabular}


and responsibilities in relation to Emily (e.g. the right to see her) regardless of whether Sam and Christina agree to this

Mike should not be considered Emity's parent but should still have some rights and resporsibilities in relation to Emily (e.g. the right to see her) if Sam and Christina agree to this

Mke should neither be considered Emity's parent nor have any rights and responsibilities in relation to

Emily wh atever the parties thirk
0

0

0

O

0

0

0

0

(1)

.

0

0

0

0

Please indicate howstrongy you agree with each d thef ollowing stamemits about your vievs on donor involvement *

\begin{tabular}{|c|c|c|c|c|c|}
\hline & $\begin{array}{c}\text { Stongly } \\
\text { agree }\end{array}$ & Agree & Indifferent & Disagree & $\begin{array}{l}\text { Stronghy } \\
\text { dis agree }\end{array}$ \\
\hline $\begin{array}{r}\text { If I were in } S \text { am and } \\
\text { Christina's position, I would } \\
\text { want twike to help raise Emily } \\
\text { as a co-parent }\end{array}$ & 0 & 0 & 0 & 0 & 0 \\
\hline $\begin{array}{l}\text { If I were in S } \mathrm{Sm} \text { and } \\
\text { Christina's position, I would } \\
\text { want wike to be heavily } \\
\text { involved in Emily's lite (e.g. } \\
\text { helping to care for her) }\end{array}$ & 0 & 0 & 0 & $U$ & $U$ \\
\hline $\begin{array}{l}\text { If I were in S Sam and } \\
\text { Christina's position, I would } \\
\text { want Mike to be inwolved in } \\
\text { Emily's life to some extent } \\
\text { (e.g. Seeing her reasonably } \\
\text { regularty) }\end{array}$ & 0 & 0 & 0 & $U$ & 0 \\
\hline $\begin{array}{l}\text { If I were in S am and } \\
\text { Christina's position, I would } \\
\text { not want Mike to be involved } \\
\text { in Emily's life at all }\end{array}$ & 0 & $\mathrm{O}$ & 0 & 0 & 0 \\
\hline
\end{tabular}

Please bridly state your reasons for the above answer (Optional) 


\section{Surrogate Scenario}

\begin{tabular}{|c|c|c|c|c|c|}
\hline & Very likehy & Quite lkely & $\begin{array}{c}\text { Itsa } \\
\text { possibility }\end{array}$ & Not weny lkely & $\begin{array}{l}\text { Not at all } \\
\text { likely }\end{array}$ \\
\hline $\begin{array}{r}\text { Would not corsider } \\
\text { surrogacy at all (perhaps } \\
\text { consider other options such } \\
\text { as adoption) }\end{array}$ & 0 & 0 & 0 & 0 & 0 \\
\hline $\begin{array}{r}\text { Ask a close female friend to } \\
\text { act as both egg donor and } \\
\text { surrogate }\end{array}$ & 0 & 0 & 0 & $\mathrm{O}$ & $\mathrm{O}$ \\
\hline $\begin{array}{r}\text { Ask a close female friend to } \\
\text { act as egg donor but make } \\
\text { contact with a surrogate } \\
\text { privatehy (e.g. through a } \\
\text { support group) }\end{array}$ & 0 & 0 & 0 & 0 & 0 \\
\hline $\begin{array}{r}\text { Ask a close female friend to } \\
\text { act as surrogate but make } \\
\text { contact with an egg donor } \\
\text { privately (e.g. through a } \\
\text { support group) }\end{array}$ & 0 & 0 & 0 & $U$ & $\mathcal{U}$ \\
\hline $\begin{array}{l}\text { Make contact with both a } \\
\text { surrog ate and an egg donor } \\
\text { privateby (e.g. through a } \\
\text { support group) }\end{array}$ & 0 & 0 & 0 & 0 & 0 \\
\hline $\begin{array}{l}\text { Go through an agency (either } \\
\text { abroad or in the UK) to make } \\
\text { contad with a potential } \\
\text { surrogate and go through a } \\
\text { licersed fertility clinic to find } \\
\text { an egg donor }\end{array}$ & 0 & 0 & $U$ & $\Theta$ & U \\
\hline $\begin{array}{l}\text { Use all available legal } \\
\text { avenues to find a surrogate } \\
\text { and egg donor }\end{array}$ & 0 & 0 & 0 & 0 & 0 \\
\hline
\end{tabular}

Please briely state your reasons for theabove answer (Optional) 
donor. The lawas it currently sands grants Susan legal motherhood and thepart ner who contributed the sperm legal fatherhood. The other pertner would have no legal connection to the child. However Susan is happy for Alex and Pete to obtain a parenta order making both Alex and Pate legal parents which means that Susan woud have no legal connedion to the child (Scott). Susan is willingt o be involved in Scott's if e as much or as little as Alex and Pate would like. *

Assuming such a parental order has been made in favour of Alex and Pete, please indicate hou strongly you agr ee with each of the following statements about the default position the law should take

$\begin{gathered}\text { Strongly } \\ \text { agree }\end{gathered}$
$\begin{gathered}\text { Susan should be considered } \\ \text { Scotts parent alongside Alex } \\ \text { and Pete, with equal legal } \\ \text { rights in relation to Scott } \\ \text { regardless of whether Alex } \\ \text { and Pete agree }\end{gathered}$

Susan should be corsidered Scott's parent alongside Alex and Pete, with equal legal rights in relation to $S$ cott if Alex and Pete agree

Sus an should be corsidered Scotts parent alongside Alex and Pete, with femer legal right in relation to $S \cot t$ regardless of whether Alex and $P$ ete agree

Sus an should be considered Scott's parent alongside Alex and Pete, with fever legal rights in relation to Scott if Alex and Pete agree

Susan should not be corsidered Scotts parent but should still have some rights and resporsibilities in relation to Scott (e.g. the right to see him) regardless of whether Alex and Pete agree

Susan should not be corsidered Scotts parent but should still have some rights and resporsibilities in relation to Scott (e.g. the right to see him) if Alex and Pete agree

Susan should neither be corsidered Scotts parent nor have any rights and responsibilities in relation to Scott wh atever the parties feel

Assuming such a parental order tas been made in favour of Alex and Pete, please indicate howstrongly you agee with esch of the following staments about your views on donor involvement * 


\begin{tabular}{|c|c|c|c|c|c|}
\hline & $\begin{array}{c}\text { Strongly } \\
\text { agree }\end{array}$ & Agree & Indifferent & Disagree & $\begin{array}{l}\text { Stronghy } \\
\text { dis agree }\end{array}$ \\
\hline $\begin{array}{l}\text { If I were in Alex and Pete's } \\
\text { position, I would want Sus an } \\
\text { to help rase Scott as a co- } \\
\text { parent }\end{array}$ & 0 & $\mathrm{O}$ & 0 & 0 & 0 \\
\hline $\begin{array}{l}\text { If I were in Alex and Petels } \\
\text { position, I would want Sus an } \\
\text { to be heavihy inwolved in } \\
\text { Scotts life (e.g. helping to } \\
\text { care for himi) }\end{array}$ & 0 & 0 & 0 & $U$ & U \\
\hline $\begin{array}{l}\text { If I were in Alex and Pete's } \\
\text { position, I would want Sus an } \\
\text { to be involved in Scotts life } \\
\text { to some extent (e.g. Seeing } \\
\text { him re as on ably regularhy) }\end{array}$ & 0 & 0 & 0 & 0 & $\mathrm{O}$ \\
\hline $\begin{array}{l}\text { If I were in Alex and Pete's } \\
\text { position, I would not want } \\
\text { Sus an to be immohed in } \\
\text { Scotts life at all }\end{array}$ & 0 & 0 & 0 & $U$ & $\Theta$ \\
\hline
\end{tabular}

Please bridly tate your reasons for the above answer

Alex and Pate have decided to acopt the offer from their friend Danni to act as surrogate and use an anonymous egg donor. The lawas it ourrertly stands grants Danni legal motherhood and the partner who contributed the sperm legal fatherhood. Nether the other partner nor the egg donor would have any legal connection to thechild. Howeser Danni is happy for Alex and Pete to obtain a parental order making both Alex and Pele legal parents which mears tha Danni would have no legal connection to the child (.tames). Danni is willing to be involved in Jemess life as much or as little as Alex and Pete woud like."

Assuming such a parental order has been made in favour of Alex and Pete, please indicate how stronghy you agree with each of the following statements ab out the default position the law should take

\begin{tabular}{|c|c|c|c|c|c|}
\hline & $\begin{array}{l}\text { Strongly } \\
\text { agree }\end{array}$ & Agree & Indifferent & Dis agree & $\begin{array}{l}\text { Stronghy } \\
\text { disagree }\end{array}$ \\
\hline $\begin{array}{l}\text { Danni should be corsidered } \\
\text { James's parent alongside } \\
\text { Alex and Pete, with equal } \\
\text { legal rights in relation to } \\
\text { James regardless of whether } \\
\text { Alex and Pete agree }\end{array}$ & 0 & 0 & 0 & 0 & 0 \\
\hline $\begin{array}{l}\text { Danni should be corsidered } \\
\text { James's parent alongside } \\
\text { Alex and Pete, with equal } \\
\text { legal right in relation to } \\
\text { James if Alex and Pete agree }\end{array}$ & 0 & 0 & 0 & 0 & 0 \\
\hline
\end{tabular}

Dannishould be corsidered James's parent alongside Alex and Pete, with fewer legal rights in relation to 
James regardless of whether Alex and Pete agree

Danni should be corsidered James's parent alongside Alex and Pete, with fewer legal rights in relation to James if Alex and Pete agree

Danni should not be corsidered James's parent but should still have some rights and resporsibilities in relation to James (e.g. the right to see him) regardless of whether Alex and Pete

agree

Danni should not be corsidered James's parent but should still have some rights and resporsibilities in relation to James (e.g. the right to see him) if Alex and Pete agree

Danni should neither be corsidered James's parent

nor have any rights and responsibilities in relation to Jarnes wh atever the parties .

.

$\begin{array}{lllll}0 & 0 & 0 & 0 & 0\end{array}$

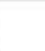

$\begin{array}{lllll}0 & 0 & 0 & 0 & 0\end{array}$




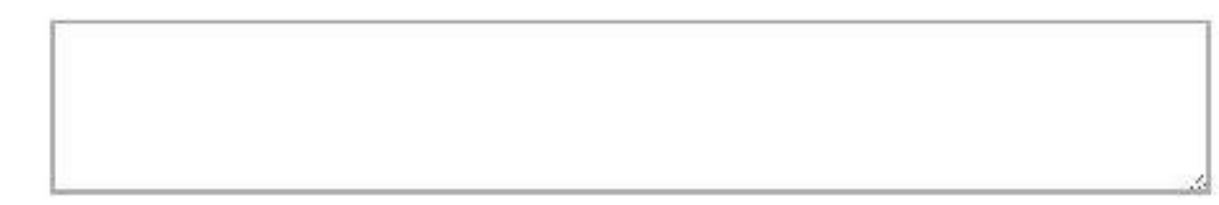

Page $6 \quad$ After page 5 Continue to next page

\section{Personal Circumstances}

How many children do you have? *

How many of your children were concel ved using ART? *

What are the ages of your children who were conceived using ART? (if aplicable)

Howwere your 'ART' children concelved? (if applicable)

e.g. Mhy 6 year old son was conceived using donor sperm and 4 ye ar old daughter was conceived using a traditional surrogate

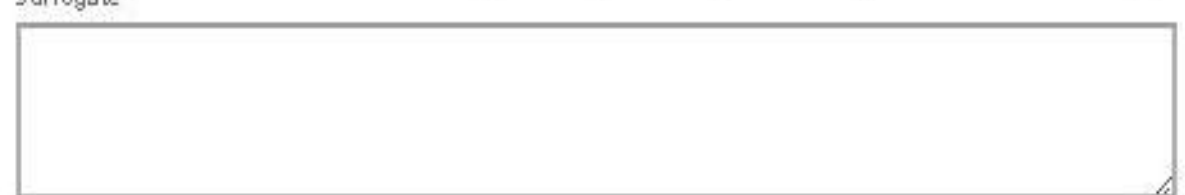

Were any of the issues diseussed in previous sedions relevant consideraions when you (and your partner) were undergoingtreatment? (if applicable)

Please try to expand on how these issues affected your thirking in relation to ART

Do you currently have any arrange mert s in place for maintaining donorigurrogate involvement in you child(ren)'s life? (if applicable)

Please exp and on your reasors for this 
Do you have any futher commert s that you woud like to add about these issues or this study? (optiona)

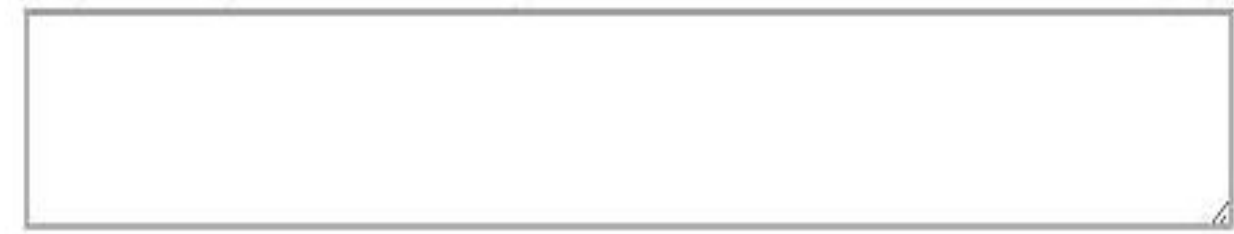

Thank you for taking the time to complete this questionnaire. If you are happy to be contacted for a follow up interview, please leave your name, e-mail address and a contact telephone number. We will arrange the interview via e-mail in the first instance unless you state below that you would prefer us to telephone.

Contact Dedails (optiona)

Please le ave your name, e-mail address and telephone number. These detaik will be kept confidential and stor ed separately fromyour questionnaire arsiners 


\section{Appendix 2: Example Interview Guide}

OK to record?

\section{Opening Remarks}

Thank you for agreeing to participate in this study.

It's been a couple of weeks now since you completed the questionnaire. So I would just like to remind you of some of things that were in the information sheet and consent form for that if that's ok?

Firstly, participation in this study is entirely voluntary. So if at any point you do not feel comfortable answering a question or you want to end the interview, you are free to do so. In addition, your answers will remain confidential and will be stored anonymously so that they cannot be attributed to you. Finally, if at any time you want me to clarify something or explain what I mean, please don't hesitate to ask. Are you quite happy with all of that?

The interview should last about $30-45$ minutes. There will be two main sets of questions, one relating to donor/surrogate involvement in the child's life and the other about legal recognition as a parent. Before we get to that though...

\section{Introductory Question}

1. Perhaps you could begin by telling me a little bit about your experiences with assisted reproduction technology. I believe you mentioned in the questionnaire that your 15 year old son was conceived using donor sperm. So perhaps you could just elaborate on how you came to make the choices you did about having children in this way?

a. What other options did you consider? Did you see any potential downsides to this option? Why did you settle on this option in the end? In hindsight, has it worked out the way you had hoped?

\section{Donor/Surrogate Involvement}

2. If I can just remind you of the first bank of questions in the questionnaire, you were presented with a hypothetical situation where an infertile couple (Sam and Christina) needed a sperm donor in order to have a child. The questionnaire presented you with a range of options and asked how likely you would be to consider each of these options. The options included using an anonymous donor or a known donor and arranging insemination privately or seeking treatment in a clinic. Each of these would have different legal consequences. I believe you indicated that if you were in their situation that you would not want a known donor but would rather use an anonymous donor receiving treatment at a licensed clinic and that that was in fact similar to the situation you were in with your then husband. Is that right? 
a. Perhaps you could elaborate on why you would not want to engage in a co-parenting project, for example, with a known donor or have the donor heavily involved in the child's life?

b. Sam and Christina could be a heterosexual or homosexual couple. Would that affect your views on whether the donor should be involved in the child's life? Do you think it would be in the best interests of the child for the donor to be involved

c. Although you personally would not want the donor involved in the child's life to any great extent you indicated that you thought the parties should be allowed to agree amongst themselves the extent to which the donor was involved in child's life, including the donor being considered a co-parent alongside the couple. Can you envisage a situation where all the parties might want to create a co-parenting arrangement? How realistic do you think it is that people might want to do that? Do you think people might be discouraged from doing that because the law only recognises two parents of a child? Do you think the law should recognise more than two parents? Why?

3. The questionnaire then went on to present a situation where an infertile couple (Alex and Pete) needed a surrogate in order to have a child. It explained that the surrogate would be considered the legal mother of the child until a court order was obtained, which the surrogate would have to consent to. In this case, the scenario involved a traditional surrogate who was genetically related to the child. I believe you indicated that you were not at all likely to use a surrogate if you were in that situation but that again the parties should be able to decide on the extent of the surrogate's involvement. Is that right?

a. Do you feel that surrogate involvement in the child's life presents different or similar issues to donor involvement? Do you feel differently or the same about surrogate involvement as you do about donor involvement? Why?

4. The final scenario asked you to consider a situation involving a gestational surrogate who was not genetically related to the child because the couple has used an anonymous egg donor.

a. What impact does the fact that the surrogate is not genetically related to the child have on your views about surrogate involvement in the child's life?

\section{Legal Recognition of Donor/Surrogate}

5. Do you know of anyone or have heard of anyone who might benefit from the law recognising more than two parents or who might be in a situation similar to those described in the questionnaire? Tell me about it...

a. Do you think this would be particularly beneficial for same-sex couples? Would it have any appeal for heterosexual couples in your opinion? 
6. I would be grateful if you would be willing to pass on details of the study because at the moment I am struggling to get participants, particularly in same-sex relationships but of course only if you feel comfortable doing that.

7. Do you think the status of being formally recognised as a parent is important and what impact do you think the donor being recognised as a parent alongside the infertile couple would have on the family?

a. Is it important that people who are biologically related to the child are considered as parents as much as possible or is it perhaps more important that the intentions of the parties determine who is the parent?

b. Do you think the effect would be positive or negative and would their be any risks or benefits associated with it?

c. What does being a parent and being recognised as a parent mean to you?

\section{Concluding Questions}

8. Would you say your views have changed in any way as a result of having participated in this study? Did it perhaps make you consider these issues in more depth than you had previously?

9. My final question is whether you might know of anyone else who would be interested in participating in this study?

That pretty much concludes the interview Thank you very much for your time and for the answers you have given. Do you have comments or questions you'd like to raise about the study or any of the issues that we have discussed?

I see that you've said that we can retain your contact details for future research so I may well be in touch again in the future if that's still alright?

Thanks again for your participation. 
Appendix 3: Table of Participants' Jurisdiction

\begin{tabular}{|c|c|}
\hline North America & E\&W \\
\hline Sherry & Eric \\
\hline Annabel & Dianne \\
\hline Sonia & Anna \\
\hline Carmen & Cathy \\
\hline Vinnie & Connie \\
\hline Anne-Marie & Susan \\
\hline Tammy & Erica \\
\hline & Julie \\
\hline
\end{tabular}




\section{Appendix 4: Chi Square Contingency Tables - Friends as Donors and Surrogates}

Table 1: Donor vs Traditional Surrogate (Ask Friend)

\begin{tabular}{|c|c|c|c|c|c|c|}
\hline & \multicolumn{3}{|c|}{ Friend as traditional surrogate } & \multirow[b]{2}{*}{ Total } \\
\hline & & & Not Likely & Possibility & Likely & \\
\hline \multirow{6}{*}{$\begin{array}{l}\text { Friend } \\
\text { as } \\
\text { donor }\end{array}$} & Possibility & Count & 2 & 2 & 3 & 7 \\
\hline & & Expected Count & 4.7 & 1.6 & .8 & 7.0 \\
\hline & Not Likely & Count & 12 & 1 & 0 & 13 \\
\hline & & Expected Count & 8.7 & 2.9 & 1.4 & 13.0 \\
\hline & Likely & Count & 4 & 3 & 0 & 7 \\
\hline & & Expected Count & 4.7 & 1.6 & .8 & 7.0 \\
\hline \multirow[t]{2}{*}{ Total } & & Count & 18 & 6 & 3 & 27 \\
\hline & & Expected Count & 18.0 & 6.0 & 3.0 & 27.0 \\
\hline
\end{tabular}

Table 2: Donor vs Gestational Surrogate (Ask Friend)

\begin{tabular}{|c|c|c|c|c|c|c|}
\hline & \multicolumn{3}{|c|}{$\begin{array}{c}\text { Friend as gestational } \\
\text { surrogate }\end{array}$} & \multirow[b]{2}{*}{ Total } \\
\hline & & & Possibility & Not Likely & Likely & \\
\hline \multirow{6}{*}{$\begin{array}{l}\text { Friend } \\
\text { as } \\
\text { donor }\end{array}$} & Possibility & Count & 4 & 1 & 2 & 7 \\
\hline & & Expected Count & 1.8 & 3.9 & 1.3 & 7.0 \\
\hline & Not Likely & Count & 0 & 11 & 2 & 13 \\
\hline & & Expected Count & 3.4 & 7.2 & 2.4 & 13.0 \\
\hline & Likely & Count & 3 & 3 & 1 & 7 \\
\hline & & Expected Count & 1.8 & 3.9 & 1.3 & 7.0 \\
\hline \multirow[t]{2}{*}{ Total } & & Count & 7 & 15 & 5 & 27 \\
\hline & & Expected Count & 7.0 & 15.0 & 5.0 & 27.0 \\
\hline
\end{tabular}




\section{Bibliography}

Allen, Mary, 'Violence and voice: using a feminist constructivist grounded theory to explore women's resistance to abuse' (2011) 11 Qualitative Research 23.

Bainham, Andrew, 'Arguments about parentage' (2008) 67(2) Cambridge Law Journal 322.

Bainham, Andrew, 'Parentage, Parenthood and Parental Responsibility: Subtle, Elusive Yet Important Distinctions' in Bainham, Andrew, Shelley Day Sclater and Martin Richards (eds), What is a parent? : a socio-legal analysis (Hart Pub., Oxford 1999).

Bainham, Andrew, 'Family Law in a Pluralistic Society' (1995) 22 Journal of Law and Society 234.

Bainham, Andrew and others, What is a parent? : a socio-legal analysis (Hart Pub., Oxford 1999).

Baker Katharine, 'Bionormativity and the Construction of Parenthood' (2008) 42 Georgia Law Review 649.

Bampton, R. and Cowton C.J., 'The E-Interview' (2002) 3(2) Forum Qualitative Social Research 9.

Banakar, Reza and Max Travers, Theory and method in socio-legal research (Oñati international series in law and society, Hart Publishing, Oxford 2005).

Bano, Samia, "Standpoint', 'Difference' and Feminist Research' in Banakar, Reza and Max Travers (eds), Theory and method in socio-legal research (Oñati international series in law and society, Hart Publishing, Oxford 2005).

Barlow, Anne, Carol Burgoyne and Janet Smithson, 'The Living Together Campaign - An investigation of its impact on legally aware cohabitants' (2007) Research Series 5/07.

Barter, Christine and Emma Renold, 'The use of vignettes in qualitative research' (1999) 25 Social Research Update.

Bottomley, Anne and Simone Wong (eds), Changing contours of domestic life, family and law: Caring and sharing (Oñati international series in law and society, Hart Publishing, Oxford 2009).

Bowen, Glen, 'Grounded Theory and Sensitizing Concepts' (2006) 5(3) International Journal of Qualitative Methods 12.

Bryman, Alan, Social research methods (3rd edn Oxford University Press, Oxford 2008).

Cabinet Office, Families in Britain (The Stationary Office, London 2008). 
Callus, Thérèse, 'First 'Designer Babies', Now À La Carte Parents' (2008) Family Law 143.

Campbell, CM and Paul Wiles, 'The Study of Law in Society in Britain' (1976) 10 Law and Society Review 553.

Charmaz, Kathy, Constructing grounded theory (Sage Publications, Thousand Oaks, Calif. 2006).

Charmaz, Kathy, 'Grounded Theory in the 21st Century: Applications for Advancing Social Justice Studies' in Denzin, Norman K. and Yvonna S. Lincoln (eds), The SAGE handbook of qualitative research (3rd edn Sage Publications, Thousand Oaks, Calif. 2005).

Charmaz, Kathy, 'Grounded Theory: Objectivist and Constructivist Methods' in Denzin, Norman K. and Yvonna S. Lincoln (eds), The SAGE handbook of qualitative research (2nd edn Sage Publications, Thousand Oaks, Calif. 2000).

Corbin, Juliet M. and Anselm L. Strauss, Basics of qualitative research : techniques and procedures for developing grounded theory (3rd edn Sage Publications, Inc, Thousand Oaks, Calif. 2008).

Cotterrell, Roger, 'Subverting Orthodoxy, Making Law Central: A View of Sociolegal Studies' (2002) 29 Journal of Law and Society 632.

Cotterrell, Roger, Law's community: legal theory in sociological perspective (Oxford socio-legal studies, Clarendon, Oxford 1995).

Cox, Barbara, 'Alternative Families' (2000) Wisconsin Women's Law Review 93.

Creelman, Janet A.E. and Roma M. Harris, 'Coming Out: The Information Needs of Lesbians' (1993) 10(3) Collection Building 37.

Creswell, John W., Qualitative inquiry and research design: choosing among five traditions (Sage Publications, Thousand Oaks, Calif. 1998).

Curasi, Carolyn Folkman, 'A critical exploration of face-to-face interviewing vs. computer-mediated interviewing' (2001) 43(4) International Journal of Market Research 361.

Dempsey Deborah, 'Conceiving and Negotiating Reproductive Relationships: Lesbians and Gay Men Forming Families with Children' (2010) 44 Sociology 1145.

Department of Health, Adoption and Permanence Taskforce Second Report (DoH, London 2002).

Diduck, Alison, "If only we can find the appropriate terms to use the issue will be solved': Law, identity and parenthood' (2007) 19(4) Child and Family Law 


\section{Quarterly 1.}

Diduck, Alison, Law's Families (Butterworths law in context series, Butterworths, London 2003).

Dimsey, Mariel, 'Multi-parent Families in the 21st Century' in Boele-Woelki, Katharina and Sverdrup, Tone (eds), European Challenges in Contemporary Family Law (European Family Law, Intersentia, Antwerp 2008).

Douglas, Gillian, An introduction to family law (Clarendon law series, 2nd edn Oxford University Press, Oxford 2004).

Dworkin, Ronald, Taking rights seriously (Duckworth, London 1977).

Dyson, Sue, The option of parenthood (Sheldon, London 1993).

Eekelaar, John and Mavis Maclean (eds), Family law (Oxford readings in sociolegal studies, Oxford University Press, Oxford 1994).

Fineman, Martha Albertson, The neutered mother, the sexual family, and other twentieth century tragedies (Routledge, New York; London 1995).

Foucault, Michel, The History of Sexuality. Volume 1: An Introduction (Penguin, Harmondsworth 1979).

Freeman, M.D.A, 'Towards a Critical Theory of Family Law' (1985) 38 Current Legal Problems 153.

Frith, Lucy et al. 'UK Gamete Donors' Reflection on the Removal of Anonymity' (2007) 22(6) Human Reproduction 1675.

Glaser, Barney G., Theoretical sensitivity: advances in the methodology of grounded theory (Sociology Press, Mill Valley, Calif. 1978).

Glaser, Barney G. and Anselm L. Strauss, The discovery of grounded theory: strategies for qualitative research (Observations, Weidenfeld \& Nicolson, London 1968).

Glennon, Lisa, "Obligations between adult partners: Moving from form to function?' (2008) 22(1) International Journal of Law, Policy and the Family 22.

Glennon, Lisa, 'Fitzpatrick v. Sterling Housing Association LTD - An Endorsement of the Functional Family' (2000) 14 International Journal of Law, Policy and the Family 226.

Hart, H. L. A., 'Definition and Theory in Jurisprudence' in Essays in jurisprudence and philosophy (Clarendon, Oxford 1983). 
Herring, Jonathan, Family law (Longman law series, 5th edn Longman, Harlow 2011).

Hill, John Lawrence, 'What Does it Mean to be a Parent--The Claims of Biology as the Basis for Parental Rights' (1991) 66 N Y U L Rev 353.

Hodson, Loveday and ILGA Europe, 'The Rights of Children Raised in Lesbian, Gay, Bi-sexual or Transgender Families: A European Perspective' (2008).

Hogben Susan and Justine Coupland 'Egg Seeks Sperm. End of Story...? Articulating Gay Parenting in Small Ads for Reproductive Partners' (2005) 11(4) Discourse and Society 459.

Hughes, Rhidian, 'Considering the Vignette Technique and its Application to a Study of Drug Injecting and HIV Risk and Safer Behaviour' (1998) 20(3) Sociology of Health and IIIness 381.

Jackson, Emily, 'What is a Parent?' in Diduck, Alison and Katherine O'Donovan (eds), Feminist Perspectives on Family Law (Routledge-Cavendish, London 2006).

Jamieson, Janet, 'Negotiating Danger in Fieldwork on Crime: A Researcher's Tale' in Linkogle, Stephanie and Geraldine Lee-Treweek (eds), Danger in the field: risk and ethics in social research (Routledge, London 2000).

Jolly, Simon, 'Family Law' in Philip Thomas (ed) Socio-Legal Studies (Dartmouth, Aldershot 1997).

Jones, Caroline, 'The identification of "parents" and "siblings": new possibilities under the reformed Human Fertilisation and Embryology Act ' in Wallbank, Julie A., Shazia Choudhry and Jonathan Herring (eds), Rights, gender, and family law (Routledge, Abingdon 2010).

Jones, Caroline, 'Parents in Law: Subjective Impacts and Status Implications around the Use of Licensed Donor Insemination' in Diduck, Alison and Katherine O'Donovan (eds), Feminist perspectives on family law (Routledge-Cavendish, London 2006).

Lacey, Nicola, Unspeakable subjects: feminist essays in legal and social theory (Hart, Oxford 1998).

Lefaucheur, Nadine, 'French Tradition of Anonymous Birth: The Lines of Argument' (2004) 18 International Journal of Law, Policy and the Family 319.

Lind, Craig and Tom Hewitt, 'Law and the complexities of parenting: parental status and parental function' (2009) 31(4) Journal of Social Welfare and Family Law 391.

Lind, Craig, 'Responsible Fathers: Paternity, the Blood Tie and Family Responsibility' in Bridgeman, Jo, Heather Keating and Craig Lind (eds), Responsibility, Law and the Family (Ashgate Publishing, Aldershot 2008). 
Lowe, Nigel, 'A study into the rights and legal status of children being brought up in various forms of marital or non-marital partnerships and cohabitation:

A Report for the attention of the Committee of Experts on Family Law of the Council of Europe ' (2009).

Mann, Chris and Fiona Stewart, Internet Communication and Qualitative Research: A Handbook for Researching Online (Sage, London 2000).

Mason, Jenifer, Qualitative Researching (Sage, London 2002)

McCandless, Julie and Sally Sheldon, 'The Human Fertilisation and Embryology Act (2008) and the Tenacity of the Sexual Family' (2010) 73(2) MLR 175.

Millbank, Jenni, 'The Limits of Functional Family: Lesbian Mother Litigation in the Era of the Eternal Biological Family' (2008) 22 International Journal of Law, Policy and the Family 149.

Morgan, D. H. J., Family connections: an introduction to family studies (Polity, Cambridge 1996).

Nettleton, Sarah and others, 'The Reality of Virtual Social Support' in Woolgar, Steve (ed), Virtual society?: technology, cyberbole, reality (Oxford University Press, Oxford 2002).

Olsen, Hope. 'Quantitative "Versus" Qualitative Research: The Wrong Question' $<$ http://www.ualberta.ca/dept/slis/cais/olson.htm> accessed on 19 April 2011.

Reece, Helen, 'The Paramountcy Principle' (1996) 49 Current Legal Problems 267

Richards, Martin, 'Divorcing Children: Roles for Parents and the State' in Maclean, Mavis and Jacek Kurczewski (eds), Families, politics and the law: perspectives for East and West Europe (Clarendon, Oxford 1993).

Schutz, Alfred, The problem of social reality (Nijhoff, The Hague 1962).

Shultz, Marjorie Maguire, 'Reproductive Technology and Intent-Based Parenthood: An Opportunity for Gender Neutrality' (1990) Wisconsin Law Review 297.

Smith, Leanne, 'Is Three a Crowd: Lesbian Mothers' Perspectives on Parental Status in Law' (2006) 18(2) Child and Family Law Quarterly 231.

Smith, Marjorie, 'New Stepfamilies - a descriptive study of a largely unseen group' (2003) 15(2) Child and Family Law Quarterly 185.

Sturges, J. E. and K. J. Hanrahan, 'Comparing Telephone and Face-to-Face Qualitative Interviewing: A Research Note' (2004) 4 Qualitative Research 107. 
Teddlie Charles and Fen Yu, 'Mixed Method Sampling: A Typology with Examples' (2007) 1(1) Journal of Mixed Methods Research 77.

Van Beuren, Geraldine, 'Child Rights in Europe, Convergence and Divergence in Judicial Protection' (2008).

Wallbank, Julie A., 'Reconstructing the HFEA 1990: Is Blood Really Thicker Than Water?' (2004) Child and Family Law Quarterly 387.

Weeks, Jeffrey, Invented Moralities: Sexual Values in an Age of Uncertainty (Polity Press, Cambridge 1995).

Zanghellini, Aleardo, 'Lesbian and Gay Parents and Reproductive Technologies: The 2008 Australian and UK Reforms' (2010) 18(3) Feminist Legal Studies 227.

Zanghellini, Aleardo, 'Who is Entitled to Parental Responsibility - Biology, Caregiving, Intention and the Family Law Act 1975 (CTH): A Jurisprudential Feminist Analysis' (2009) 35 Monash U L Rev 147.

\section{Newspaper Articles and Websites}

Daily Telegraph, 'David Cameron: family matters to children more than income' 11 January 2010

http://www.hfea.gov.uk/infertility-facts.html\#1248

http://www.uptodate.com/contents/patient-information-evaluation-of-the-infertilecouple

http://www.hfea.gov.uk/donor-conception-births.html

http://www.cdc.gov/art/ART2008/PDF/ART 2008 Full.pdf

http://www.surrogacyuk.org/

http://www.councilforresponsiblegenetics.org/pageDocuments/KAEVEJ0A1M.pd f

http://www.bbc.co.uk/programmes/b013y232

http://www.bbc.co.uk/programmes/b0146g40

http://www.psychologytoday.com/blog/genetic-crossroads/201108/surrogacyand-baby-selling-another-fertility-industry-scandal

http://www.hfea.gov.uk/docs/Latest long term data analysis report 9106.pdf.pdf 